Noname manuscript No.

(will be inserted by the editor)

\title{
Instrumental requirements for the study of Venus' cloud top using the UV imaging spectrometer VeSUV
}

\author{
Emmanuel Marcq • Franck Montmessin . \\ Jérémie Lasue · Bruno Bézard · Kandis \\ L. Jessup - Yeon Joo Lee • Colin F. \\ Wilson • Benjamin Lustrement • Nicolas \\ Rouanet · Gabriel Guignan
}

Received: date / Accepted: date

\author{
Abstract Ultraviolet spectral imaging has been a powerful tool to investi- \\ gate the cloud top of Venus, allowing for measurement of several minor gases \\ (especially $\mathrm{SO}_{2}, \mathrm{SO}, \mathrm{O}_{3}$ ), of cloud top aerosol's microphysical properties and \\ of atmospheric dynamics through tracking of the unevenly distributed UV \\ absorber. After a brief review of recent UV instruments that orbited around \\ E.Marcq \\ LATMOS/IPSL, UVSQ, Université Paris-Saclay, Sorbonne Université, CNRS, Guyancourt, \\ France \\ F. Montmessin \\ LATMOS/IPSL, UVSQ, Université Paris-Saclay, Sorbonne Université, CNRS, Guyancourt, \\ France \\ J. Lasue \\ IRAP, Université de Toulouse, CNRS, CNES, UPS, Toulouse, France \\ B. Bézard \\ LESIA, Observatoire de Paris, Université PSL, CNRS, Sorbonne Université, Université de \\ Paris, 5 place Jules Janssen, Meudon, France \\ K. L. Jessup \\ Southwest Research Institute (SwRI), 1050 Walnut St., Suite 300, Boulder CO, 80302, USA \\ Y. Lee \\ Zentrum für Astronomie und Astrophysik, Technische Universität Berlin, Berlin, Germany \\ C. F. Wilson \\ AOPP, Clarendon Laboratory, Parks Road, Oxford OX1 3PU, UK \\ B. Lustrement \\ LATMOS/IPSL, UVSQ Université Paris-Saclay, Sorbonne Université, CNRS, Guyancourt, \\ France \\ N. Rouanet \\ LATMOS/IPSL, UVSQ Université Paris-Saclay, Sorbonne Université, CNRS, Guyancourt, \\ France \\ G. Guignan \\ LATMOS/IPSL, Sorbonne Université, UVSQ, CNRS, Paris, France
}


Venus, we present the results of a state-of-the-art radiative transfer model from Marcq et al. (2020) to derive the spectral resolution and Signal-to-Noise ratio (SNR) required to derive abundances of these gases, retrieve optical properties of the aerosols beyond our current knowledge. This leads us to propose a two-channel UV hyperspectral push-broom imager called VeSUV (standing for Venusian Spectroscopy in UV) whose technical characteristics will improve on existing measurements by a factor of at least 2, and which is well suited to the integration into the payload of future low Venus orbit platforms such as the proposed EnVision mission to ESA M5 call.

Keywords Venus · Ultraviolet · Instrumentation · Atmosphere

\section{Introduction}

Although Venus displays very little contrast in the visible range, it is known since at least the late 1920s (Ross, 1928) that the spatial and spectral structure of the reflected sunlight at cloud top level is much richer in the near UV range, with a prominent absorption peaking near $365 \mathrm{~nm}$ (Heyden et al., 1959; Pollack et al., 1979, 1980; Pérez-Hoyos et al., 2018). Permanent to semi-permanent spatial features include a characteristic Y-bow shape aligned with the zonal superrotation, as well as polar haze caps whose brightness varies on a multiyear timescale (Dollfus et al., 1960), as does the global UV albedo (Lee et al., 2019). This absorber is responsible for about half the total amount of absorbed sunlight in Venus' atmosphere, and thus plays a major role in the radiative balance and atmospheric dynamics (Haus et al., 2016).

The nature of this UV absorber is still debated, with candidate species as diverse as iron chloride (Zasova et al., 1981; Krasnopolsky, 2017), disulphur dioxide (Frandsen et al., 2016, 2020) or various sulphur compounds (Hapke and Nelson, 1975; Toon et al., 1982), some even suggestingg a possible biological origin (Limaye et al., 2018). The chemical lifetime of this absorber near cloud top appears to be long relative to horizontal motions; this makes its absorption signature particularly suitable for short-term tracking of zonal and meridional winds at the cloud top (Khatuntsev et al., 2013; Hueso et al., 2015; Horinouchi et al., 2018). Readers interested in a more detailed review of UV cloud tracking are advised to refer to Sánchez-Lavega et al. (2017).

Another major insight provided by UV observations of Venus comes from spectroscopy, with the first detection of sulphur dioxide $\left(\mathrm{SO}_{2}\right)$ above the clouds by Barker (1979) using the space telescope International Ultraviolet Explorer (IUE). Subsequent observations of $\mathrm{SO}_{2}$ absorption have been acquired over the decades from Venus orbiting missions, ground based observations and other space borne telescope platforms. After the first IUE observations, Pioneer Venus was the first to record strong temporal variability and a secular decrease in $\mathrm{SO}_{2}$ abundance spanning two orders of magnitude in less than a decade (Esposito et al., 1979, 1988), that could be a sign of a transient atmospheric destabilization through active volcanism (Esposito, 1984). After a relative neglect for a decade (1995 to 2005), similar near-decadal scale secular 
trends were inferred from the long-time base observations obtained by Venus Express (Marcq et al., 2011; Marcq et al., 2013; Marcq et al., 2020; Vandaele et al., 2017a,b) while both ground-based (Encrenaz et al., 2012, 2013, 2016, 2019, 2020a; Jessup et al., 2015) and Venus Express observations confirmed that Venus' cloud top $\mathrm{SO}_{2}$ abundance exhibit strong short-term as well as spatial variability. Other gaseous species detected at cloud top through their UV absorption are sulphur monoxide (SO) (Na et al., 1990, 1994; Jessup et al., 2015 ) and even more recently ozone $\left(\mathrm{O}_{3}\right)$ (Marcq et al., 2019) - even though ozone was already known to exist at higher altitudes near $100 \mathrm{~km}$ thanks to UV stellar occultations (Montmessin et al., 2011).

Finally, the backscattered solar UV also provides clues to estimate the cloud top level aerosols' microphysical properties. The phase angle dependence at small phase angle, the so called optical glory phenomenon, is especially sensitive to a particle size and a variance of size distribution (García Muñoz et al., 2014; Markiewicz et al., 2014; Petrova et al., 2015a; Lee et al., 2017), especially when also including its degree of linear polarization (Kawabata et al., 1980; Knibbe et al., 1998; Braak et al., 2002). Their local time variations have been poorly understood, even though the photochemical aerosol formation process is directly linked to the $\mathrm{SO}_{2}$ and $\mathrm{SO}$ gases that will be measured simultaneously.

Both ESA's Venus Express (2006-2014) (Titov et al., 2006) and JAXA's Akatsuki (2015-) (Nakamura et al., 2016) orbiters include UV sensitive instruments, whose description and main results are detailed in the next section $\S 2$. Section $\S 3$ deals with the expected accuracy of UV measurements with respect to SNR and spectral resolution, as well as required spatial resolution. Finally, Section $\S 4$ describes a UV instrument concept whose technical specifications allow for a significant improvement on the previous measurements according to our modeling.

\section{Recent Scientific heritage}

In this section, we summarize the most recent UV datasets available for Venus, in order to assess how we can improve on their results.

\subsection{UV Spectroscopy}

\subsubsection{Low-resolution}

SPICAV-UV was the UV channel of the SPICAV spectrometer suite (Bertaux et al., 2007) on board ESA's orbiter Venus Express. It was able to operate in stellar occultation mode, as well as in nadir or near-nadir viewing geometry. Its spectral resolution was $\sim 1.5 \mathrm{~nm}$ over the $110-320 \mathrm{~nm}$ interval.

In the nadir mode, SPICAV explored Venus' dayside cloud top UV signature (Marcq et al., 2011; Marcq et al., 2013; Marcq et al., 2020). These studies 
recorded the cloud top sulphur dioxide $\mathrm{SO}_{2}$ abundance thanks to its absorption bands centered near 215 and $283 \mathrm{~nm}$, and a plausible range of sulphur monoxide SO thanks to its absorption band centered near $215 \mathrm{~nm}$. Marcq et al. (2019) then discovered about 10 ppbv of ozone $\mathrm{O}_{3}$ thanks to its so-called Hartley absorption band centered near $255 \mathrm{~nm}$.

It could also measure the UV reflectance of the cloud top out of any absorption bands from atmospheric gases, thereby yielding constraints on the unknown UV absorber spatial and temporal variability - although its UV absorption is maximal near $365 \mathrm{~nm}$, absorption is still noticeable at shorter wavelengths (Pérez-Hoyos et al., 2018; Marcq et al., 2019).

The moderate spectral resolution of SPICAV-UV only allowed the observation of absorption bands rather than resolving the individual absorption lines that make up these bands (Fig. 1). Therefore, it suffered from several degeneracies: between $\mathrm{SO}_{2}$ and $\mathrm{SO}$, so that the $\mathrm{SO}: \mathrm{SO}_{2}$ ratio had to be assumed (usually $10 \%$, based on high resolution spectroscopic studies detailed in $§ 2.1 .2$ ), but also between the cloud top altitude (measured using the strong $\mathrm{CO}_{2}$ absorption at wavelengths shorter than $220 \mathrm{~nm}$ ) and the spectral slope of the UV absorber (Marcq et al., 2020).

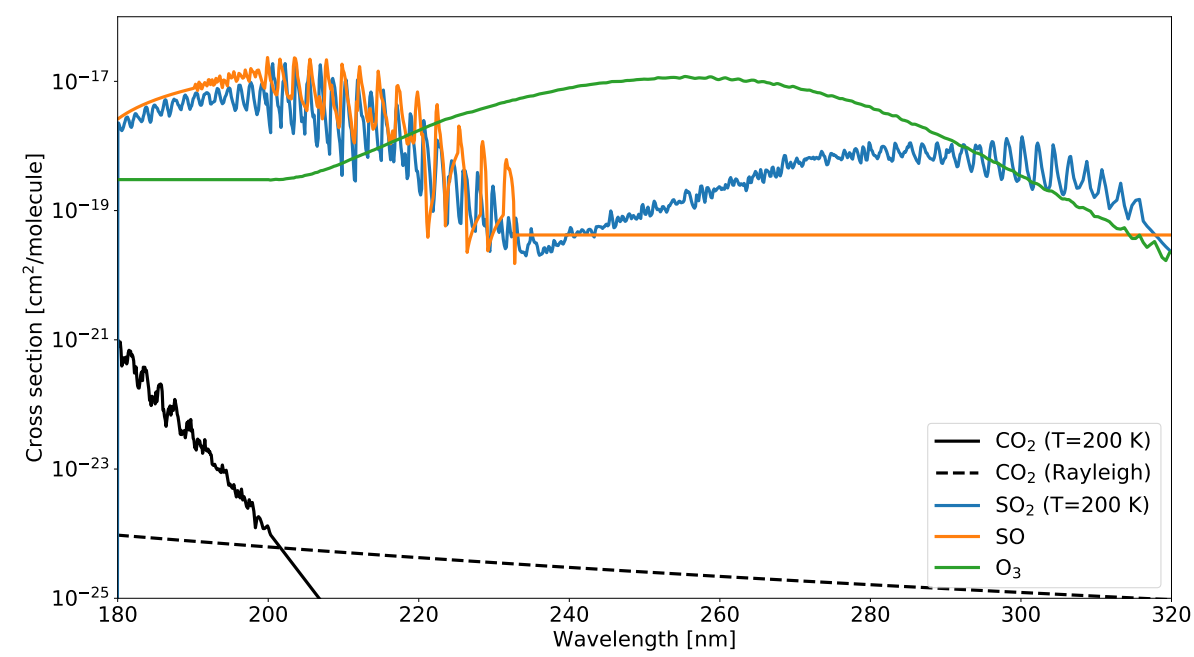

Fig. 1 Absorption cross-sections of gaseous minor species in the spectral range observed by SPICAV-UV. $\mathrm{SO}_{2}$ cross-section is identical to Jessup et al. (2015), whereas SO cross-section from 190 to $230 \mathrm{~nm}$ is taken from Phillips (1981) and extrapolated beyond. $\mathrm{O}_{3}$ cross-section comes from Sander et al. (2003) at wavelengths larger than $205 \mathrm{~nm}$, and $\mathrm{CO}_{2}$ absorption cross-section from Parkinson (2003) - Rayleigh scattering from $\mathrm{CO}_{2}$ from Sneep and Ubachs (2005).

SPICAV-UV confirmed the very high variability of $\mathrm{SO}_{2}$ above cloud top already evidenced by OUVS on board Pioneer Venus two decades earlier. Two different regimes of vertical transport were established by Marcq et al. (2013): one with a higher abundance in $\mathrm{SO}_{2}$ and a decreasing trend with 
increasing latitude in both hemispheres, consistent with an efficient supply of $\mathrm{SO}_{2}$ from the lower atmosphere via vertical transport at low latitudes. And then, another with a much lower abundance in $\mathrm{SO}_{2}$ and a suppression (or even a reversal) of the latitudinal gradient, suggesting during these periods the inefficient resupply of $\mathrm{SO}_{2}$ via vertical transport. The $\mathrm{SO}_{2}$-rich regime was more prevalent in the earlier part of the mission (2006 to 2010), whereas the $\mathrm{SO}_{2}$-poor regime dominated the second half of the mission. These data also revealed a temporal anti-correlation between the UV absorber and $\mathrm{SO}_{2}$ (Marcq et al., 2020), hinting at a possible conversion between both species which if proven true would support the hypothesis of a sulphur-bearing UV absorber.

\subsubsection{High-resolution}

Currently available UV spectroscopic observations with the highest spectral resolution $(0.27 \mathrm{~nm})$ were performed by the STIS imaging spectrometer on board the Hubble Space Telescope (HST). Despite the difficulty of pointing at a target (Venus) so close to the Sun, Jessup et al. (2015) could acquire spectra along six slits positions on the day side of Venus, on Dec. 28th 2010, Jan. 22nd 2011 and Jan. 27th 2011. These spectra had a spatial sampling of $\sim 50 \mathrm{~km}$ and covered the 170-317 nm spectral range. Jessup et al. (2015, their Fig. 3) show a typical spectrum, that exhibits distinct absorption lines of both sulphur oxides $\mathrm{SO}$ and $\mathrm{SO}_{2}$, thus enabling separate measurements with a typical retrieval accuracy of $\sim 20 \%$ for both $\mathrm{SO}$ and $\mathrm{SO}_{2}$ and within a factor of 2 for their ratio (Jessup et al., 2015, their Fig. 8).

From these observations, Jessup et al. (2015) were able to confirm the inversion of the latitudinal gradient of $\mathrm{SO}_{2}$ within a month, supporting the theory that these distributions are directly related to variable periods of high and low $\mathrm{SO}_{2}$ vertical mixing first reported by SPICAV-UV (Marcq et al., 2011; Marcq et al., 2013). SO and $\mathrm{SO}_{2}$ were found to be highly correlated, with typical $\mathrm{SO}: \mathrm{SO}_{2}$ ratios ranging from 7 to $18 \%$. The absolute UV cloud brightness derived from the Hubble observations was also used to support the assignment of the absolute $365 \mathrm{~nm}$ brightness evident in the VMC and Akatsuki images obtained at similar observational phase angles ( $\S 2.2$ ). This work led to the identification of a multi-year decreasing trend in the cloud top albedo (Lee et al., 2019). This darkening trend was also evident in the SPICAV observations, in addition to the strong anti-correlation in the abundances of the unknown UV absorber and $\mathrm{SO}_{2}$ gas at the cloud top (Marcq et al., 2020).

\subsection{UV Imaging}

In contrast to the aforementioned spectrometers, UV imagers emphasize wide field-of-views and spatial (angular) resolution at the expense of the wavelength coverage (usually a few discrete wavelengths through narrow band filters). The most recent ones have been VMC (Markiewicz et al., 2007) on board Venus 
Express, as well as UVI (Yamazaki et al., 2018) on board JAXA's orbiter Akatsuki. We will also discuss in this section the VIRTIS-M data (Drossart et al., 2007) aboard Venus Express. This instrument was an imaging spectrometer of relatively low spectral resolution, ans most of its science exploitation in its $\mathrm{UV}$-visible range was performed using it as an imager at several wavelengths, which is why we list it in this section rather than the previous one.

Both instruments VMC and UVI have comparable specifications: UVI observations were performed at 283 and $365 \mathrm{~nm}$ (focusing on $\mathrm{SO}_{2}$ absorption and the unknown UV absorber respectively), whereas VMC's only UV filter is also centered on $365 \mathrm{~nm}$ where spatial UV contrasts are maximal. UVI has a field-of view of $12^{\circ} \times 12^{\circ}\left(\mathrm{VMC}: 17.5^{\circ} \times 17.5^{\circ}\right)$, and its angular sampling is $0.2 \mathrm{mrad}$ (VMC: $0.7 \mathrm{mrad}$ ). Depending on the altitude of their respective orbital platforms, this translates into spatial sampling at cloud level ranging from 0.2 to $76 \mathrm{~km}$ according to Yamazaki et al. (2018) (VMC: from 0.2 to $45 \mathrm{~km})$.

This spatial resolution enabled detection of UV contrasts ranging from planetary scale (like the aforementioned Y-bow shape) to mesoscale: sub-solar mottled convection patterns (Titov et al., 2012, their Fig. 7), middle latitude streaks (Titov et al., 2008) or gravity waves (Piccialli et al., 2014) whose spatial wavelengths range from 3 to $20 \mathrm{~km}$. They could also track these UV contrasts as proxy for horizontal wind speeds (Khatuntsev et al., 2013; Horinouchi et al., 2018) and monitor the long term evolution of the $365 \mathrm{~nm}$ albedo (Lee et al., 2015). The vertical distribution of the UV absorber was also suggested to vary over the 5 years of Venus Express (Lee et al., 2015). The global view of UVI helped to find a clear correlation between the UV absorbers $\left(\mathrm{SO}_{2}\right.$ and the unknown absorber) and the cloud top altitudes inferred from the $\mathrm{CO}_{2}$ absorption band at $2.02 \mu \mathrm{m}$ (Lee et al., 2020). Their finding implies that the UV absorbers' abundances and the cloud top altitude are associated with a common atmospheric dynamics, such as the global scale planetary waves.

Study of the UV phase function of Venus has also been performed by both VMC (Markiewicz et al., 2014; Petrova et al., 2015a) and UVI (Lee et al., 2017). Thanks to the glory backscattering feature peaking near a phase angle of $10^{\circ}$, they could constrain the effective radius of the so-called "mode 2 particles" (which constitute the bulk of the upper and middle opacity in the visible-UV range) between 1 and $1.4 \mu \mathrm{m}$ with a comparatively small variance in size distribution, with evidence for a decrease of their effective radius with increasing latitude on the morning side. Interestingly, the retrieved refractive index of these particles was found to exceed the value for pure $\mathrm{H}_{2} \mathrm{SO}_{4}$ whereas IR observational constraints rather point to a $\mathrm{H}_{2} \mathrm{SO}_{4}: \mathrm{H}_{2} \mathrm{O}$ ratio ranging between 75\% and 90\% (Barstow et al., 2012; Arney et al., 2014). This suggests a contamination of these droplets with contaminants that may also be candidates for the UV absorber, e.g. sulphur and/or chlorine based compounds (Petrova et al., 2015a,b). Finally, taking advantage of the wide array of observational geometries allowed by the large FoV of VMC, Molaverdikhani et al. (2012) were able to constrain the vertical distribution of the UV absorber (well mixed above $63 \mathrm{~km}$ or restricted to a thin layer near $71 \mathrm{~km}$ ) and 
well as its latitudinal variations (365 nm optical depth halved near both poles compared to the equator).

On the other hand, VIRTIS-M-vis was an imaging spectrometer covering the 270-1100 $\mathrm{nm}$ range with a spectral sampling of about $2 \mathrm{~nm}$ with a $0.25 \times 64 \operatorname{mrad}^{2}\left(\approx 0.015^{\circ} \times 3.4^{\circ}\right)$ instantaneous field of view. Full spectral cubes could be obtained through scanning the second spatial dimension using the secondary telescope mirror. Its spectroscopic capabilites were somewhat hampered by straylight and calibration issues, therefore most of its scientific results came from UV imagery instead. In particular, upper cloud tracking in the 360-400 nm was performed by Hueso et al. (2015), constraining the global circulation and wind shear in relation with dynamics at other levels (SánchezLavega et al., 2016; Hueso et al., 2012), and hinting at an intense atmospheric wave activity. These waves were studied previously by Peralta et al. (2008) who observed wavepackets over high southern latitudes extending for several hundreds of kilometers, a typical wavelength in the $90-320 \mathrm{~km}$ range, with a zonal velocity of a few tens of $\mathrm{m} / \mathrm{s}$ relatively to the local zonal wind speed. The typical spatial resolution of the VIRTIS-M data used for atmospheric dynamics studies was in the range $16-50 \mathrm{~km}$. In contrast with the shorter wavelength systems observed by Piccialli et al. (2014), these scarcely occuring wave packets exhibited no correlation with high topographic features.

\section{Scientific Requirements}

Based on the aforementioned review of the most recent UV observations of Venus, we can formulate the following scientific objectives for our proposed UV investigation as included in the payload of a low Venusian orbiter similar to the ESA M5 candidate mission En Vision described here below.

\subsection{The proposed EnVision mission}

\subsubsection{EnVision Science Goals}

The EnVision mission (Ghail et al., 2017) lies at the heart of the ESA Cosmic Vision programme whose objectives are to identify the conditions for planet formation and the emergence of life, and to understand how the Solar System works. In this context, EnVision is dedicated to the study of the Venus planet. The key questions for this mission to address are linked to:

1. Activity How geologically active is Venus?

2. History How have the surface and interior of Venus evolved?

3. Climate How are Venus' atmosphere and climate shaped by geological processes?

The payload of EnVision shall include a synthetic aperture radar, a radio science experiment, a subsurface radar sounder and finally a spectrometer suite named VenSpec (Helbert et al., 2019) including three instruments: the 
thermal IR imager VenSpec-M, the high-resolution IR spectrometer VenSpec$H$, and finally the VeSUV instrument as its UV channel VenSpec- $U$.

\subsubsection{VenSpec-U Science Goals}

The VenSpec-U project is part of the EnVision mission as a core element whose main scientific objectives are to:

- Search for atmospheric effects of geological activity, in order to determine how much outgassing is occurring (if any), and how the atmospheric chemistry is coupled with surface and subsurface geochemistry and weathering cycles.

- Study how mesospheric gas variations are linked to possible volcanic activity, in order to identify the causes of variability in the mesospheric sulphur dioxide.

- Study how cloud and particulate variability is linked to possible volcanic activity, in order to detect plumes of volcanic ash or sulphate clouds that volcanism would cause, and to understand any link between the Venus sulphuric acid cloud and the possible volcanic activity.

The VenSpec-U/VeSUV project is consequently primarily dedicated to the monitoring of the distribution and spatial and temporal variations of sulphurbearing gases $\left(\mathrm{SO}, \mathrm{SO}_{2}\right.$ ) and unknown particulate absorber at the cloud tops, through spectral analysis of backscattered sunlight on the dayside of Venus. When combined with the two other IR sensitive channels included in the VenSpec suite, detailed studies of the chemistry and transport supporting Venus sulphur species distributions between the surface and the cloud top may be completed: for example combining - $\mathrm{U}$ channel $\mathrm{SO}_{x}$ measurements with high resolution IR spectra from the $-\mathrm{H}$ channel yielding $\mathrm{H}_{2} \mathrm{O}$ and OCS measurements both below and above the clouds will provide critical data needed to study Venus' aerosol formation process. Considering the focus on gaseous measurements, no additional polarimetric capability is expected at this stage.

Finally, it should be noted that nadir (or nadir-like) spectroscopy using backscattered sunlight is only sensitive to column densities above an effective backscattering altitude - about $70 \mathrm{~km}$ in the UV range (Marcq et al., 2019), which defines the effective cloud top altitude. Conversion into local mixing ratios relies on external assumptions for the vertical profiles of the considered species and scattering species (whether particulate or gaseous).

$\mathrm{SO}_{2}$ SPICAV-UV typical relative accuracy was in the $20 \%$ to $50 \%$ range, which was enough to characterize the spatial and temporal variability of $\mathrm{SO}_{2}$. However, there were some $(<10 \%$ of the total) observations where $\mathrm{SO}_{2}$ fell below its detection threshold (about a few ppb at $70 \mathrm{~km}$ ). Taking into account the improvements in UV sensor technology, and in order to better characterize the low $\mathrm{SO}_{2}$ regime, we aim for a 2 -fold improvement in our $\mathrm{SO}_{2}$ relative accuracy compared to SPICAV-UV (10\% relative uncertainty). 
SO A better understanding of the sulphur chemistry at cloud top level requires simultaneous measurements of $\mathrm{SO}_{2}$ and $\mathrm{SO}$ with a comparable accuracy. Existing HST-STIS data only constrain their ratio within a factor of 2 , we aim here for a relative accuracy on the $\mathrm{SO}: \mathrm{SO}_{2}$ of $20 \%$ or better. Another indirect motivation for this value comes from minimizing the bias on $\mathrm{SO}_{2}$ measurements caused by assuming a wrong value of the $\mathrm{SO}: \mathrm{SO}_{2}$ ratio (see $\S 3.3 .2)$.

$U V$ absorber Since this absorber acts as a tracer for the convective activity responsible for the $\mathrm{SO}_{2}$ supply at cloud top, monitoring the spatial and spectroscopic variations in UV range caused by this absorber is fully included in our sulphur chemistry investigations.

Cloud particles Finally, the interplay between gaseous and condensed phases within the clouds is also poorly understood. Any insight about the UV scattering particles that can be obtained from UV observations would help in understanding the highly coupled microphysics, homogeneous and heterogeneous chemistry processes that take place at cloud top level.

Also, all the above mentioned measurements should be as representative as possible in order to build a full climatology of the observable parameters. Therefore, a global coverage in excess of $60 \%$ of the whole day side (with respect to latitude, longitude and local solar time) is needed, with any gaps as small as possible $(<10 \%$ in any dimension $)$ and if possible minimizing any spurious correlation.

\subsubsection{Observation Strategy}

Radar observations require a spacecraft altitude as low as possible, and ideally a circular orbit. Spatial coverage, mass and budget considerations resulted in several trade-offs, resulting in a planned low eccentricity polar orbit whose altitude varies between about 150 and $525 \mathrm{~km}$ (period: $94 \mathrm{~min}$ ), with a variable pericenter latitude (low to middle latitudes) during the planned duration of the mission. This working orbit requires an initial two year long aerobraking phase during which no scientific observations are possible (mainly due to heat dissipation). Therefore, no instrument can get a synoptic instantaneous hemispheric coverage on board EnVision.

Instead, the most cost-effective solution to enable both imaging and spectroscopic capabilities in this orbital configuration is the so-called "pushbroom" observation mode, with the nadir observed swath slowly precessing with each orbit relative to the Venusian surface. This will also allow for successive observations relative the same ground spot, which will help in addressing the topic of surface-atmosphere interactions (see $\S 3.2 .3$ ).

Data link rate is also a primary concern for En Vision, so that one instrument cannot operate continuously. In the current version of the operation scenario, VenSpec-U is allowed to operate for four consecutive dayside half-orbits every 16 orbits (totalling 24 Earth hours). This enables the above mentioned short-term overlapping, and results in a $>90 \%$ global planetary coverage (rel- 
ative to the surface) at the end of the nominal mission (6 Venusian sidereal days, or "cycles").

\subsection{Spatial requirements}

The spatial resolution requirements would be driven mainly by our need to understand the vertical transport as well as interactions of the sulphured gaseous species with clouds - more specifically, resolving convection and wave-cloud interactions. On the other hand, long term, climatological mapping of sulphured gases would only need large scale measurements over a longer time period.

\subsubsection{Support from previous observations}

In order to assess more quantitatively the horizontal scales visible in the UV range, we have performed a high pass filtering (at a $1 \sigma 10-\mathrm{km}$ length scale) for some publicly available $365 \mathrm{~nm}$ images from the UVI instrument on board Akatsuki with the finest spatial resolution available, less than $3 \mathrm{~km} /$ pixel (Fig. 2). Significant convective and wave activity can be seen for typical length scales of a few kilometers.
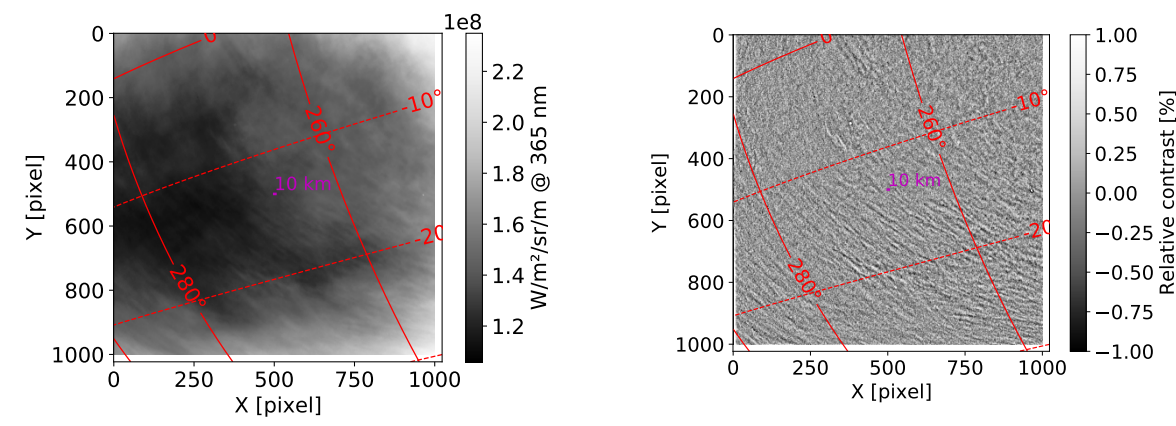

Fig. 2 Left: Calibrated UVI image of Venus acquired from Akatsuki spacecraft on 201609-04. Red lines show the latitude/longitude grid. 1 pixel equals $3 \mathrm{~km}$ at cloud top level at the center of this image. Right: High-pass filter applied to the left image, computed as local relative departure between the calibrated image shown left and its $10 \mathrm{~km}$ gaussian smoothed version.

Interestingly, this 1-10 km length scale arises in two different, unrelated phenomena. First of all, this kilometric length scale is consistent with the smaller features observed by VMC on board Venus Express and already mentioned in Sec. 2.2, like mottled convective features close to the subsolar point (Titov et al., 2008). Aside from convective activity, the other kind of dynamical targets we may investigate at this wavescale would be orography-induced gravity wave activity, e.g. near Maxwell Montes. Piccialli et al. (2014) have measured wavelengths ranging from 3 to $20 \mathrm{~km}$, in the same order of magnitude as 
the above described convective features. Similar correlations with topography were also found for intermediate wavelength systems (Peralta et al., 2017) and planetary-scale bow wave (Fukuhara et al., 2017; Kitahara et al., 2019). However, the long wavesystems found by Peralta et al. (2008) at various cloud altitudes did not correlate with any surface features.

\subsubsection{Support from mesoscale modeling}

Another clue showing the scientific importance of the $\sim 10 \mathrm{~km}$ horizontal scale length comes from the LMD-IPSL mesoscale models of the atmosphere of Venus (Lefèvre et al., 2017, 2018). This model includes visible and IR radiative forcing by gases and aerosols, and can simulate (Fig. 3) the convective activity observed at cloud top near the subsolar point (Titov et al., 2008). In these simulations, the spatial extent of the convection cells (in which the UV absorber acts as a tracer) is confirmed to be on the order of $\sim 10 \mathrm{~km}$. Furthermore, these mesoscales simualtions predict that cloud top convection is restricted to lower latitudes and caused by static instabilty caused by localised UV solar heating, leading to shallow convection as suggested by Imamura et al. (2014).

Also, the similarity between the simulated vertical wind vector field and the observed convection cells implies that the observed small scale mottled contrasts would be connected with wind vectors. High spatial resolution observations could quantify this possible correlation between vertical motions and UV brightness, and would explain how the UV absorber abundances or fresh bright cloud area are evolving over upwelling or downwelling areas.

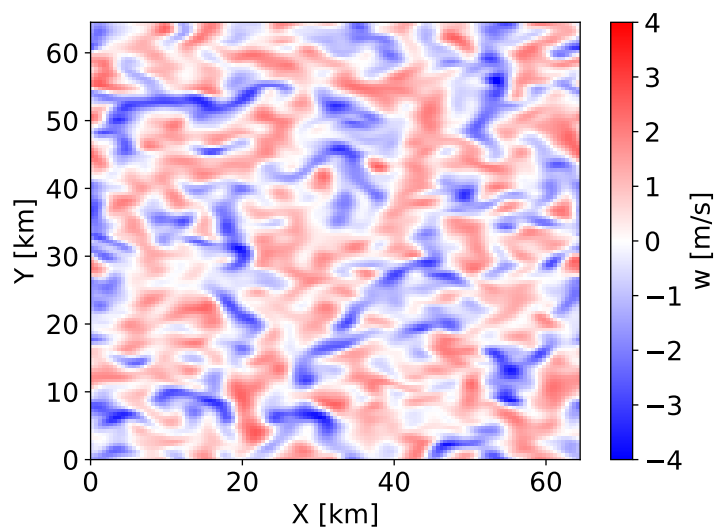

Fig. 3 Horizontal cut of the instantaneous vertical wind at an altitude of $70 \mathrm{~km}$ at the subsolar point from the mesoscale model of Lefèvre et al. (2018).

Other mesoscale simulations were performed by Imamura et al. (2014) using the "Cloud Resolving Storm Simulator". They also concluded that the horizontal scale of convection cells is typically in the $10-15 \mathrm{~km}$ interval. 


\subsubsection{Spatial Field-of-view (FoV)}

The extent of the spatial transverse FoV is mainly dictated by the need to observe the spatial structure of the backscattered light over a swath at least several times larger than the above mentioned $10 \mathrm{~km}$ spatial scale. For an instrument located in low Venusian orbit $(220 \mathrm{~km})$, this translates into an angular transverse FoV of at least $20^{\circ}$. This brings two additional advantages:

- if the instrument is carried on a polar orbit, it allows for several successive (low Venusian orbit has a $\sim 80$ min period) nadir observations over the same ground spot, since the orbit will only slowly precess relative to the Venusian surface in a slow rotation. Also, since the zonal superrotation will renew the atmospheric content at cloud top between two consecutive observations, any significant correlation between these consecutive observations could be traced back to the influence of the solid surface at the cloud top level. Kouyama et al. (2017); Fukuhara et al. (2017) and Kitahara et al. (2019) showed local time dependence of topographic waves in images recorded by Akatsuki in the thermal infrared of cloud top near $10 \mu \mathrm{m}$ as well as near $283 \mathrm{~nm}$. This makes the study of gravity waves and their local time dependence possible, further constraining dynamical modeling at both global level (Navarro et al., 2018) and mesoscale level (Lefèvre et al., 2020).

- A $20^{\circ}$ wide FoV also allows for observations over a similar phase angle range, especially if some observations are performed with an emission angle different from $0^{\circ}$. This could better constrain the phase function of the upper clouds and hazes for several wavelengths bins over the spectral range of VeSUV. More specifically, in strict nadir viewing and near the subsolar point, the already mentioned glory feature, occurring only for phase angles near $\sim 10^{\circ}$, could be observed and help in constraining the cloud particle size distribution and refractive index/composition (Markiewicz et al., 2018, 2014; Rossi et al., 2015).

\subsection{Signal-to-Noise \& spectral requirements}

\subsubsection{Radiative Transfer Methods}

The forward model of Venus' UV spectral reflectance first developed by Marcq et al. (2011), updated for Marcq et al. (2013) and Jessup et al. (2015) and more recently for Marcq et al. (2019, 2020) makes use of line resolving, high resolution gaseous absorption cross-sections. This model can be run using vast array of wavelength ranges and spectral resolutions.

In order to better constrain the accuracy of $\mathrm{SO}_{2}$ and $\mathrm{SO}$ measurements derived from spectroscopic observations of Venus' cloud top, we adopted the following scheme:

1. Synthetic computation of a typical dayside reflectance spectrum of Venus observed at nadir ( $\mathrm{SO}: \mathrm{SO}_{2}$ ratio set at 0.1 , solar zenith angle of $30^{\circ}$, emis- 
sion angle of $0^{\circ}, \mathrm{SO}_{2}$ abundance of $10 \mathrm{ppbv}$ set at $70 \mathrm{~km}$, cloud top set at $73 \mathrm{~km}$, imaginary index of so-called "mode 2 " particles is set at $3 \cdot 10^{-2}$ at $250 \mathrm{~nm}$;

2. Adding of a synthetic noise whose spectral variations follow the noise expected from the reflected spectrum. This noise is then scaled to a given value of Signal-to-Noise Ratio (SNR) set at a reference wavelength of $240 \mathrm{~nm}$;

3. Retrievals using a Levenberg-Marquardt algorithm (Newville et al., 2020) based on the synthetic noised spectrum described above:

(a) on the 190 to $320 \mathrm{~nm}$ interval, similar to SPICAV-UV spectral range and sampled at twice the assumed spectral resolution, $\mathrm{SO}: \mathrm{SO}_{2}$ ratio set at 0.1 , cloud top altitude, imaginary index and $\mathrm{SO}_{2}$ abundance left as free parameters. Such a setup is identical to the fitting strategy used by Marcq et al. (2020);

(b) on the 200 to $240 \mathrm{~nm}$ interval, similar to HST/STIS spectral range and sampled at twice the assumed spectral resolution, cloud top altitude set at $73 \mathrm{~km}, \mathrm{SO}: \mathrm{SO}_{2}$ ratio, imaginary index and $\mathrm{SO}_{2}$ abundance left as free parameters.

\subsubsection{Results}

After having run the above described forward model for several values of scaled SNR and spectral resolution, we show in Fig. 4 the relative accuracy - defined as the standard error yielded by the Levenberg-Marquardt fitting algorithm divided by the prescribed parameter value - for retrieved $\mathrm{SO}_{2}$ (assuming a fixed $\mathrm{SO}: \mathrm{SO}_{2}$ ratio) on the $190-320 \mathrm{~nm}$ range, and for $\mathrm{SO}: \mathrm{SO}_{2}$ ratio on the 200-240 nm range (assuming a fixed cloud top altitude). Unsurprisingly, larger SNR values lead to a much improved accuracy, as well as improved spectral resolution/sampling.

However, $\mathrm{SO}: \mathrm{SO}_{2}$ ratio retrieval on the narrow band 200-240 $\mathrm{nm}$ - where SO exhibits a well characterized absorption cross-section (Phillips, 1981) - is relatively more sensitive to spectral resolution vs. SNR compared to $\mathrm{SO}_{2}$ retrievals - the logarithmic slope of iso-accuracy lines on Fig. 4 is $40 \%$ steeper for $\mathrm{SO}: \mathrm{SO}_{2}$ ratio compared to $\mathrm{SO}_{2}$ abundance. This is due to the fact that distinguishing between $\mathrm{SO}$ and $\mathrm{SO}_{2}$ absorption requires that the individual absorption lines (and not only the absorption bands) are resolved on the spectrum, which is the case only for a spectral resolution smaller than $1 \mathrm{~nm}$ (Fig. 5).

Also, it is interesting to compare these modeled relative accuracies with those derived from similar observations. The latest SPICAV-UV measurements (Marcq et al., 2020) typically yielded $\mathrm{SO}_{2}$ measurements with a relative uncertainty (error interval width divided by retrieved value) of 25 to $50 \%$, whereas HST/STIS line resolving observations by Jessup et al. (2015) had a typical relative uncertainty of about $50 \%$ for their retrieved $\mathrm{SO}: \mathrm{SO}_{2}$ ratio.

Keeping these values in mind, we used our forward model to investigate the bias on $\mathrm{SO}_{2}$ retrievals if the assumed $\mathrm{SO}: \mathrm{SO}_{2}$ ratio differs from its actual 

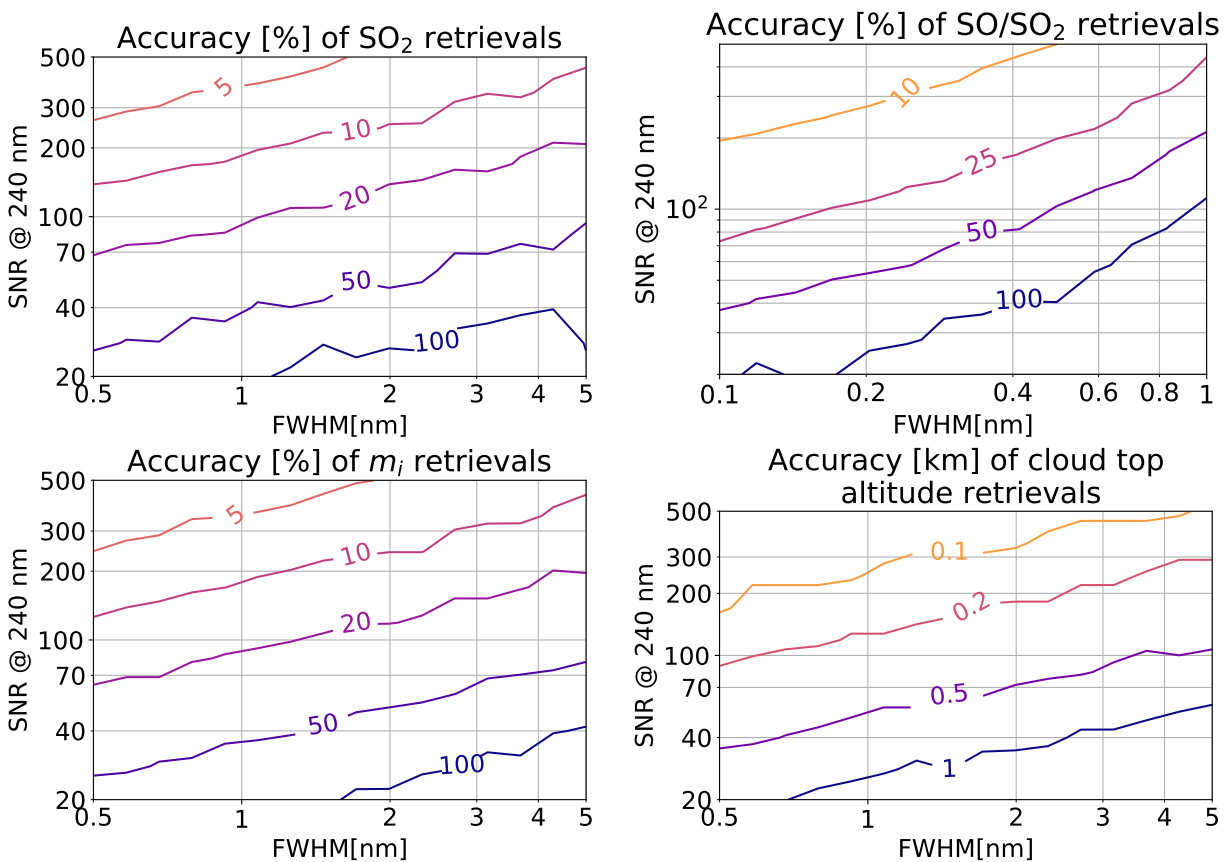

Fig. 4 Upper left: relative accuracy of $\mathrm{SO}_{2}$ retrievals with respect to $\mathrm{SNR}$ at $250 \mathrm{~nm}$ and spectral resolution full width half maximum (FWHM). Upper right: relative accuracy of $\mathrm{SO}_{2}$ retrievals with respect to $250 \mathrm{~nm}$ SNR and spectral FWHM. Lower left: relative accuracy of imaginary index retrievals with respect to $250 \mathrm{~nm}$ SNR and spectral FWHM. Lower right: Accuracy (in $\mathrm{km}$ ) of cloud top altitude retrievals with respect to $250 \mathrm{~nm} \mathrm{SNR}$ and spectral FWHM.
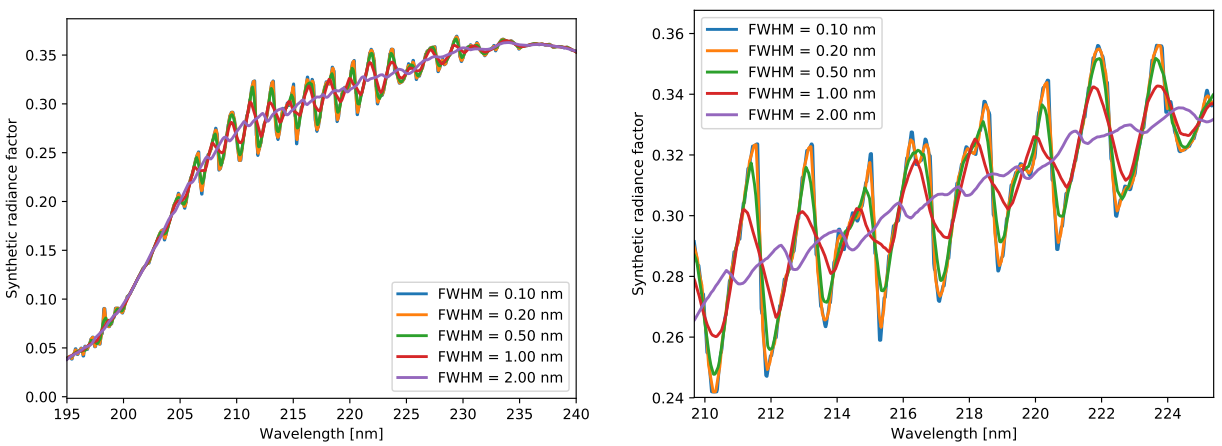

Fig. 5 Simulated radiance factors in the nominal case for various spectral full width half maxima (FWHM) using our forward model.

value. We found that a $100 \%$ increase in the assumed vs. actual $\mathrm{SO}: \mathrm{SO}_{2}$ ratio leads to a $25 \%$ overestimation of the retrieved $\mathrm{SO}_{2}$ abundance compared to its prescribed value. Therefore, in order to maintain a precision of our $\mathrm{SO}_{2}$ retrieved value well within our $10 \%$ error margin goal, we must measure si- 
multaneously the SO: $\mathrm{SO}_{2}$ ratio with an accuracy much better than $40 \%$. Our target value of a $25 \%$ relative precision for the $\mathrm{SO}: \mathrm{SO}_{2}$ ratio measurements fulfills this constraint.

\subsubsection{Spectral range}

Although the longer wavelengths within the SPICAV-UV spectral range already pointed to an increasing absorption (Marcq et al., 2019, 2020), it could not acquire reflectance data beyond $320 \mathrm{~nm}$. In principle, the visible channel $(0.25-1 \mu \mathrm{m})$ of the VIRTIS-M spectral imager (Drossart et al., 2007) would have bridged the gap to the absorption peak of the unknown UV absorber located near $365 \mathrm{~nm}$, but cross-calibration between VIRTIS and SPICAV appeared difficult to reach in the 300-400 nm range (Vlasov et al., 2019). Opportunistic spectral measurements over the whole $0.2-1.4 \mu \mathrm{m}$ range have been acquired by Pérez-Hoyos et al. (2018) using the MASCS spectrometer on board NASA's Messenger mission to Mercury. They evidenced smooth spectral variations of their retrieved imaginary index of cloud particles in the $300-600 \mathrm{~nm}$ interval and could rule out some possible compositions for the UV absorber based on these measurements, e.g. croconic acid (Hartley et al., 1989), $\mathrm{S}_{4}$ (Hapke and Nelson, 1975), or nitrosylsulphuric acid (Watson et al., 1979).

In order to constrain the spectral properties of the "unknown UV absorber" the spectral range of VeSUV must therefore reach at least $365 \mathrm{~nm}$. However, only a moderate spectral resolution is required considering that no narrow spectral features have ever been measured in this range, which would be consistent with a UV absorber embedded in a condensed phase.

\subsection{Science Traceability Matrix}

As a summary of this section, Table 1 shows a science traceability matrix for the VeSUV instrument, relating science objectives to instrumental specifications.

\section{Instrumental concept}

Here we present the so called VeSUV (standing for Venus Spectrography in $U$ ltra $V$ iolet) instrument concept, which fulfills the requirements detailed in $\S 3$. In the context of the candidate ESA M5 proposal EnVision, VeSUV is part of a spectrometer suite called VenSpec (Helbert et al., 2019), and therefore primarily known as VenSpec-U. 
Table 1 Science Traceability Matrix for VeSUV

\begin{tabular}{|c|c|c|}
\hline Science Objective & Requirement & Reference \\
\hline $\begin{array}{l}\mathrm{SO}_{2} \\
\text { Observing } \mathrm{SO}_{2} \\
\mathrm{SO}_{2} \text { precision }<10 \%\end{array}$ & $\begin{array}{l}\text { spectral range including } 190-320 \mathrm{~nm} \\
\mathrm{SNR}(250 \mathrm{~nm})>200 \text { at } 1 \mathrm{~nm} \text { sampling } \\
\text { and } \mathrm{SO}: \mathrm{SO}_{2} \text { precision }<25 \%\end{array}$ & $\begin{array}{l}\text { Marcq et al. }(2020) \\
\text { this paper }\end{array}$ \\
\hline $\begin{array}{l}\mathrm{SO} \\
\text { Observing } \mathrm{SO} \\
\text { Separating } \mathrm{SO} \& \mathrm{SO}_{2} \\
\mathrm{SO}: \mathrm{SO}_{2} \text { precision }<25 \%\end{array}$ & $\begin{array}{l}\text { spectral range including } 205-235 \mathrm{~nm} \\
\text { spectral sampling }<0.5 \mathrm{~nm} \\
\operatorname{SNR}(250 \mathrm{~nm})>100 \text { at } 0.2 \mathrm{~nm} \text { sampling }\end{array}$ & $\begin{array}{l}\text { Phillips (1981) } \\
\text { Jessup et al. (2015) } \\
\text { this paper }\end{array}$ \\
\hline $\begin{array}{l}\text { UV absorber \& clouds } \\
\text { Constraining UV absorber composition } \\
\text { Resolving small-scale convection } \\
\text { Constraining droplet properties }\end{array}$ & $\begin{array}{l}\text { spectral range extending }>365 \mathrm{~nm} \\
\text { spatial sampling }<5 \mathrm{~km} \\
\text { transverse angular } \mathrm{FoV}>20^{\circ}\end{array}$ & $\begin{array}{l}\text { Pérez-Hoyos et al. (2018) } \\
\text { Titov et al. (2008) } \\
\text { Markiewicz et al. (2018) }\end{array}$ \\
\hline $\begin{array}{l}\text { All investigations } \\
4+\text { observations over same fixed } \\
\text { spot relatively to surface }\end{array}$ & transverse spatial FoV $>100 \mathrm{~km}$ & Kouyama et al. (2017) \\
\hline $\begin{array}{l}\text { Representative data set } \\
\text { for cloud top climatology }\end{array}$ & $\begin{array}{l}\text { coverage }>60 \% \text { with each gap }<10 \% \\
\text { (wrt. lat., long., loc. time) }\end{array}$ & \\
\hline
\end{tabular}

\subsection{Instrument Description}

The VenSpec-U instrument is a dual channel UV spectral imager. The low spectral resolution "LR" channel ranges from 190 to $380 \mathrm{~nm}$ at a $2 \mathrm{~nm}$ spectral resolution and a binned spatial sampling ranging from 3 to $5 \mathrm{~km}$, while the high spectral resolution "HR" channel ranges from 205 to $235 \mathrm{~nm}$ at a $0.2 \mathrm{~nm}$ spectral resolution and a binned spatial sampling ranging from 12 to $24 \mathrm{~km}$. The spectral overlap between LR and HR channels ensures a proper crosscalibration of the more SNR-challenging HR channel on the simulateneously acquired LR baseline. This is especially welcome since this overlap occurs in the spectral range most sensitive to our main target gaseous species $\left(\mathrm{SO}_{2}\right.$ and $\mathrm{SO})$.

Each channel consists of an entrance baffle, an objective composed of two lenses and a stop diaphragm, and a spectrometer composed of a slit and a toroidal holographic grating. It also comprises a shortpass filter to reject the wavelengths above the higher limit of the bands (>240 nm for HR, > $380 \mathrm{~nm}$ for LR) and a zero-order trap to avoid straylight that may be due to internal reflections of the grating zero-order (only the first diffraction order is used). The optical layout is presented in Fig. 6. Both LR and HR slits are parallel and the optical layout is such that both channels have the same instantaneous field of view. Each slit image is then spectrally dispersed by its respective toroidal holographic grating and is focused on a shared (for cost reasons) CMOS backside illuminated detector. The spectra of LR and HR channels are dispersed one above the other on the same focal plane (Fig. 7), with very little crosscontamination between both channels. 


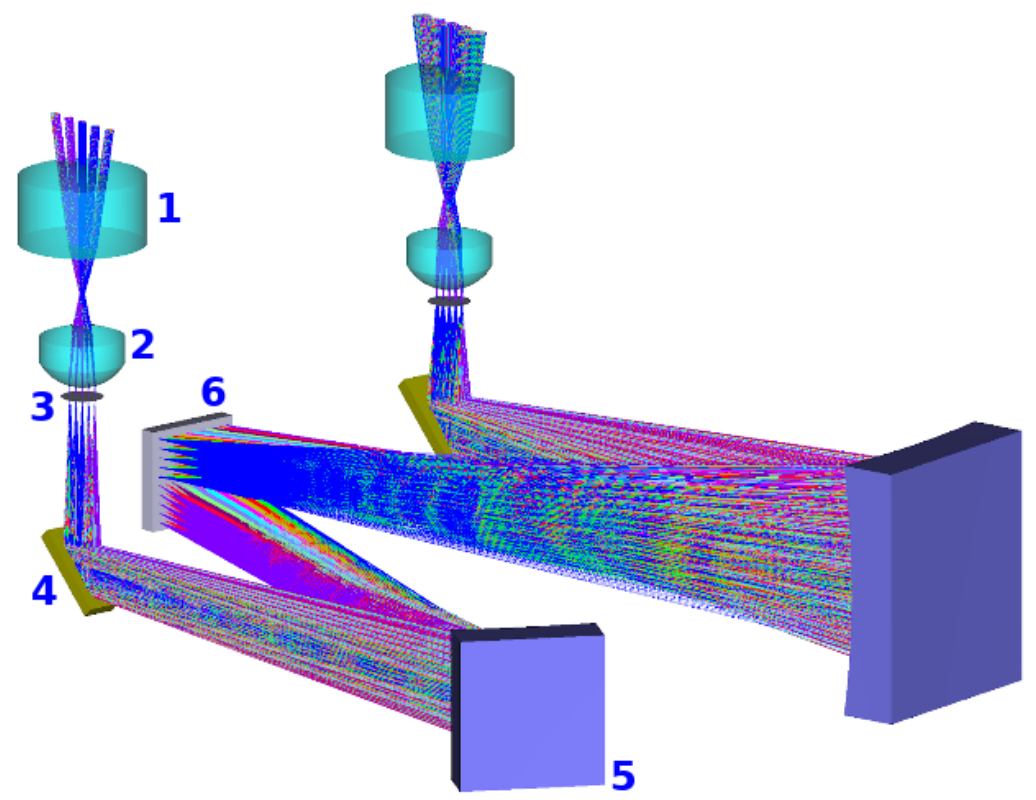

Fig. 6 VenSpec-U optical layout overview, with the HR and LR channels respectively on the left and on the right. For the HR channel: (1) Front lens; (2) Rear lens; (3) Slit; (4) Reflective filter; (5) Grating; (6) Shared sensor.

The VenSpec-U instrument includes two electronic assemblies:

- a Main Electronics unit, composed itself of a power conversion board, a data processing board, and an interface board in charge of the electrical and data interface with the subsystems and housekeeping conditioning;

- a detector frontend electronics.

The Main Electronics relies on a hybrid hardware/software mix to allow for flexibility and maintainability thanks to the software, and timing performances thanks to the hardware. The data processing board is controlled by a FPGA based on the NanoXplore architecture which offers on-ground reprogrammability while having intrinsically good immunity to radiations.

\subsection{Interfaces and resource requirements}

Fig. 8 shows the block diagram presenting the internal and external interfaces of the instrument and its subsystems.

Interfaces between VenSpec-U and spacecraft are: (1) Thermal interface providing a cold finger to cool down the detector and a thermal reference point for the electrical box and the optical bench; (2) Power interface (redundant $28 \mathrm{~V}$ ) to VenSpec-U electronics and spacecraft controlled heaters and (3) Data SpaceWire link (including ground debug EGSE). Commanding, data 


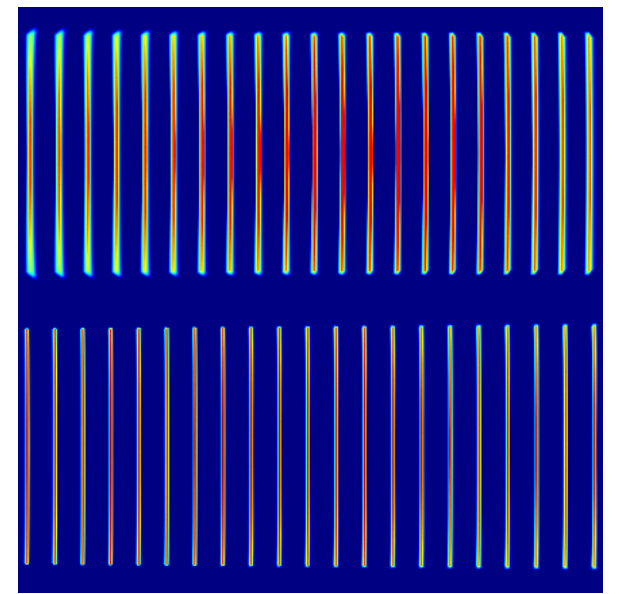

Fig. 7 VenSpec-U focal plane shared between the LR (top) and HR (bottom) channels, showing both slit images at regularly 21 spaced wavelengths covering their respective spectral ranges. The long axis of both slits provide spatial information, whereas the spectral dispersion takes place along the short axis of both slits.

Table 2 VenSpec-U instrument design summary (Current best estimates)

\begin{tabular}{|c|c|c|}
\hline $\begin{array}{l}\text { Optical objectives } \\
\text { Focal length } \\
\text { Angular FoV }\end{array}$ & \multicolumn{2}{|c|}{$\begin{array}{c}2 \text { aspherical lenses, telecentric in image space } \\
22.9 \mathrm{~mm} \\
22.5^{\circ}\end{array}$} \\
\hline Aperture & $\varnothing 4.1 \mathrm{~mm}$ & $\varnothing 2.04 \mathrm{~mm}$ \\
\hline $\begin{array}{l}\text { Spectrometer } \\
\text { Spectral range } \\
\text { Spectral resolution } \\
\text { Arms length } \\
\text { Slit size } \\
\text { Spatial magnification } \\
\text { Grating ruling density } \\
\text { Dispersion }\end{array}$ & $\begin{array}{c}\text { LR } \\
190-380 \mathrm{~nm} \\
2 \mathrm{~nm} \\
200 \mathrm{~mm} \\
9 \mathrm{~mm} \times 180 \mu \mathrm{m} \\
1 \\
500 \mathrm{gr} / \mathrm{mm} \\
9.5 \mathrm{~nm} / \mathrm{mm} \\
\end{array}$ & $\begin{array}{c}\text { HR } \\
205-235 \mathrm{~nm} \\
0.2 \mathrm{~nm} \\
200 \mathrm{~mm} \\
9 \mathrm{~mm} \times 126 \mu \mathrm{m} \\
1 \\
3110 \mathrm{gr} / \mathrm{mm} \\
1.5 \mathrm{~nm} / \mathrm{mm} \\
\end{array}$ \\
\hline $\begin{array}{l}\text { Detector } \\
\text { Physical size } \\
\text { Number of (unbinned) pixels } \\
\text { Operating temperature }\end{array}$ & \multicolumn{2}{|c|}{$\begin{array}{c}20.48 \mathrm{~mm} \times 20.48 \mathrm{~mm} \\
2048 \times 2048 \\
\approx 250 \mathrm{~K}\end{array}$} \\
\hline $\begin{array}{l}\text { Physical characteristics } \\
\text { Mass } \\
\text { Power } \\
\text { Dimensions }\end{array}$ & \multicolumn{2}{|c|}{$\begin{array}{c}6.8 \mathrm{~kg} \text { incl. maturity margin } \\
6.5 \text { to } 18.7 \mathrm{~W} \\
250 \times 280 \times 290 \mathrm{~mm}^{3}\end{array}$} \\
\hline
\end{tabular}

link to the spacecraft and power supply will be provided by a dedicated Central Control Unit (CCU). The instrument mass including maturity margin is $6.8 \mathrm{~kg}$. The power resources are $6.5 \mathrm{~W}$ in standby mode, $13.2 \mathrm{~W}$ during science observation, and $18.7 \mathrm{~W}$ for peak power. The data rate ranges from 76 to 644 $\mathrm{kbit} / \mathrm{s}$ depending on the distance to the clouds and on the spatial sampling mode. 


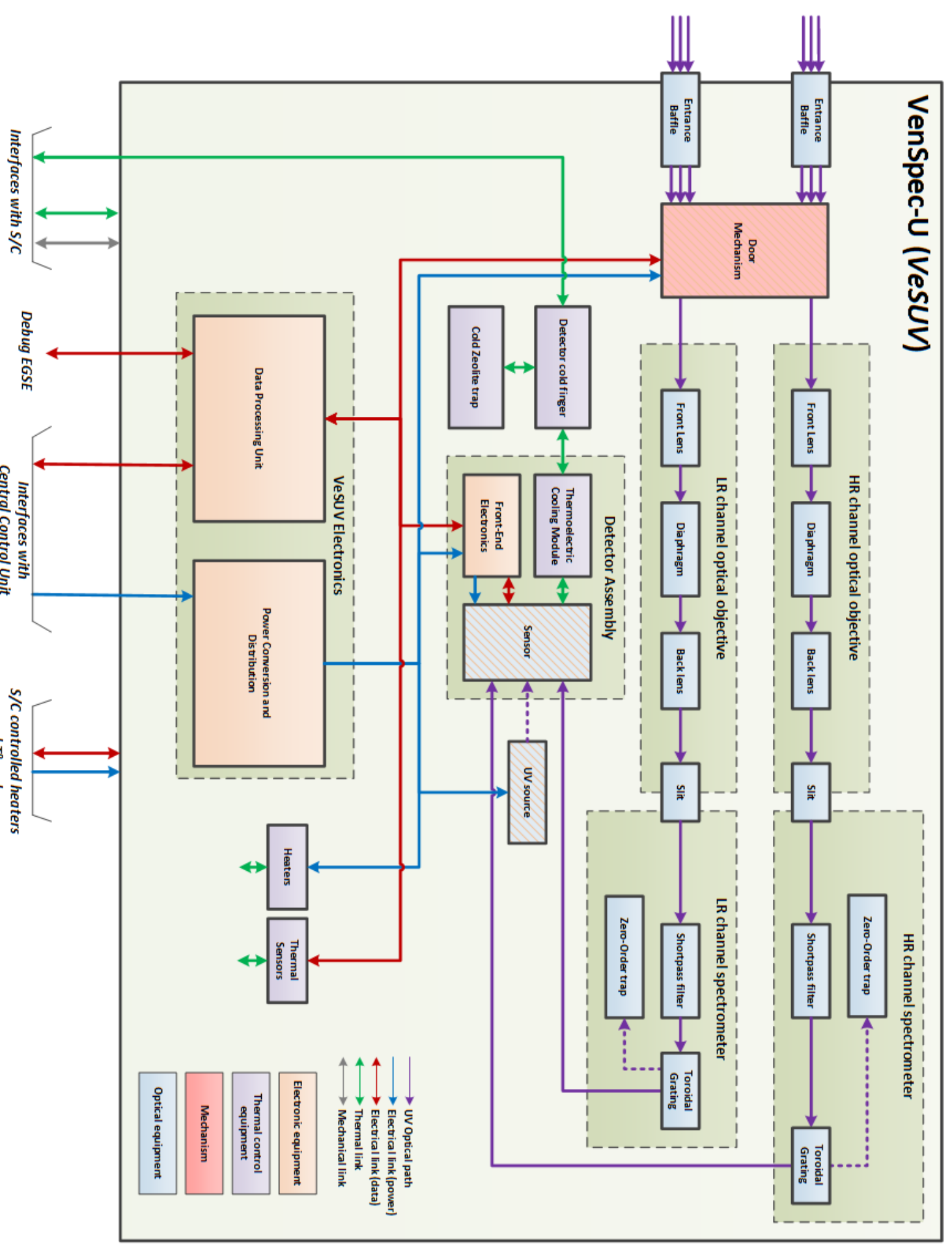


4.3 Observing Strategy

As previously mentioned in $§ 3.1 .3$, VenSpec-U nominal science operations on day side consist of four consecutive sessions of dayside observations lasting about $50 \mathrm{~min}$ each. Since the polar orbit slowly precess relatively to the surface, there is significant overlapping between these consecutive observations, allowing for a hourly timescale study of any atmospheric features that would fixed relatively to the surface. These observations are interleaved with star, internal and dark calibrations performed once or twice per month on the night side.

The identical instantaneous field of view of the two channels allows simultaneous observations of the same target as well as simultaneous calibrations on the same star. The narrow-slit axis of the detector contains the spectral information, whereas the long-slit axis contains the spatial information along the $22.5^{\circ}$ field of view of each slit. The remaining spatial direction is provided through orbital scrolling, an observational strategy known as "pushbroom". Observations can be conducted in strict nadir or near-nadir (emission angle $<30^{\circ}$ ) geometries.

Binning on the spatial axis is performed on the detector, enabling a SNR higher than 100 for the HR channel and 200 for the LR one (resulting in a coarser spatial sampling on the more dispersed HR channel). The detector will be controlled such that the integration time, the binning scheme and frame stacking are adjusted independently (and simultaneously) for each channel, giving high flexibility and providing parameters for the optimisation of each science acquisition (SNR vs. angular sampling vs. distance between the instrument and the cloud top vs. etc.). The SNR objectives are reached for a spatial sampling always smaller than $5 \mathrm{~km}$ on the LR channel, insuring the sufficient spatial resolution to investigate the cloud top convective processes at less than $10 \mathrm{~km}$ length scale $(\S 3.2)$. For the HR channel, the higher spectral resolution and lower radiance below $240 \mathrm{~nm}$ prevents any access to the $10 \mathrm{~km}$ length scale, so that our best effort while meeting the SNR objective yields a spatial sampling between 12 and $24 \mathrm{~km}$ depending on the observation.

Based on the analysis shown in Section 3.3, such SNR and spectral resolution should allow for a determination of the $\mathrm{SO}: \mathrm{SO}_{2}$ ratio with an accuracy better than $25 \%$ using the $\mathrm{HR}$ channel, and of the total $\mathrm{SO}+\mathrm{SO}_{2}$ column with an accuracy better than $10 \%$. In both cases, this will result in a significant improvement compared to the accuracy of past measurements discussed in Section 2.1. Incidentally, these SNR and spectral resolution values also yield measurements of unknown UV absorber (through its imaginary refractive index) and cloud top altitude with respective accuracies of $\sim 10 \%$ and $\sim 200 \mathrm{~m}$, much improved compared to e.g. SPICAV-UV retrievals. 


\subsection{Additional Measurement Capabilities}

Aside from its core science objectives, this instrument may incidentally measure other properties of the upper atmosphere, either through reflected solar light on the day side or aeronomic emissions on the night side.

\subsubsection{Other gaseous species}

Using the radiative transfer model described in $\S 3.3 .1$ with the instrumental SNR and spectral resolution, we were also able to compute the sensitivity of the instrument to other UV absorbing trace species that exist (or may exist) at or above Venus cloud top, using the same methodology as described in $§ 3.3$, assuming nadir viewing over typical dayside conditions. Sensitivity variations with e.g. $\mathrm{SO}_{2}$ content or haze variability should be moderate considering the climatogical range already observed by e.g. SPICAV-UV (Marcq et al., 2020).

$\mathrm{O}_{3}$ Ozone should be detectable using the LR channel in nadir viewing mode, provided its mixing ratio is more than a few ppbv at cloud top; this is about one order of magnitude improvement from the SPICAV detection at higher latitudes (Marcq et al., 2019) and may allow tracking of $\mathrm{O}_{3}$ at lower latitudes, thus better constraining coupled chemical transport and photochemistry models.

$\mathrm{ClO}$ Chlorine monoxide is an expected product from chlorine photochemistry above the clouds (Mills and Allen, 2007; Zhang et al., 2012), which is thought to interact with sulphur photochemistry in the mesosphere above the clouds. We predict a sensitivity threshold to $\mathrm{ClO}$ at about $10 \mathrm{ppbv}$ between 85 and $95 \mathrm{~km}$ where $\mathrm{ClO}$ mixing ratio should be peaking. This is about one ordre of magnitude larger than average model predictions, so that $\mathrm{ClO}$ detection is unlikely but not impossible in favourable circumstances.

$\mathrm{PH}_{3}$ Following the claims of about 20 ppb of phosphine within Venus' clouds (Greaves et al., 2020), we also investigated our sensitivity to this species, which presents an absorption band near $180 \mathrm{~nm}$. Considering the very low signal at these wavelengths, we predict a very weak sensitivity to $\mathrm{PH}_{3}$ in the 50-70 $\mathrm{km}$ altitude range, over $100 \mathrm{ppb}$. We therefore advise that remote sensing confirmation or invalidation of $\mathrm{PH}_{3}$ presence in Venus' clouds should rather be performed in the thermal IR range near $10 \mu \mathrm{m}$ (Encrenaz et al., 2020b).

\subsubsection{Large scale atmospheric dynamics}

Due to the low orbit of EnVision, even a field-of-view in excess of $20^{\circ}$ does not cover a large transverse distance projected at cloud top (on the order of 100 to $200 \mathrm{~km}$ ). Therefore, due to the zonal superrotation, the UV cloud contrasts observed during one orbit will have shifted westwards by several hundreds of kilometers when the orbiter comes back during the next orbit, 
and these constrasts will have left the field of view. This makes cloud tracking not possible with the current orbit and instrument design, except for latitudes higher than about $70^{\circ}$ where the superrotation is significantly slower than at lower latitudes. Even there, the relatively low SNR due to the high solar zenith angles prevailing near the poles could be challenging. Nevertheless, if some cloud tracking were possible, the spectroscopic capabilities of VeSUV could yield interesting results if the retrieved vector speed would differ with wavelength, as evidenced with UVI by Horinouchi et al. (2018).

Also, although wind determination by feature tracking will not be possible in general, EnVision's regular coverage will enable other types of investigations relevant to large-scale dynamics, e.g. monitoring of the latitudinal extent of the UV-bright clouds typically present at Venus' poles, and monitoring of longterm variations in UV albedo, which may be linked to long-period atmopsheric dynamical cycles (Lee et al., 2019).

\subsubsection{Night side observations}

Stellar occultations at a monthly interval are essential for the instrumental calibration. Such occultations, with a line-of-sight to the star ingressing or egressing out of the atmosphere, may also provide vertically resolved observations of the mesospheric extinction (due to both particulate matter and gaseous species), like SPICAV-UV performed in its nominal science case. A thorough knowledge of EnVision's orbit and pointing on Venus' night side would be required first in order to assess the achievable accuracy, vertical resolution and coverage with respect to latitude, local solar time and altitude range.

In the same observational geometry, limb observations of Venus could also be acquired. This would in principle allow for aeronomical studies of the upper mesosphere, since e.g. VeSUV's spectral range encompasses both $\delta$ (190$240 \mathrm{~nm})$ and $\gamma(255-270 \mathrm{~nm}$ ) bands of nitric oxide (NO) airglow (Gérard et al., 2008; Stiepen et al., 2013; Royer et al., 2016). However, the very weak intensity of the airglows compared to the solar radiation backscattered on the day side (which is the primary target and main radiometric design driver for VeSUV optical conception) would require very long integration times and/or extensive spatial binning in order to reach a workable SNR, thereby hampering severely the spatial resolution of such observations. Furthermore, current science operation scenario does not allow for VenSpec-U operating on the night side except for calibration purposes (about once a month), so that the spatial and temporal coverage would be modest. Nevertheless, we intend to study more in detail the feasibility of such aeronomical observations for an extended science case if EnVision were selected.

\subsubsection{Ultra high spatial resolution mode}

With the required spectral resolution of $2 \mathrm{~nm}$, a satisfactory SNR can only be reached for a spatial sampling larger than $3 \mathrm{~km}$ even in optimal conditions. Unfortunately, some dynamical phenomena e.g. gravity waves (Piccialli et al., 
2014), or fine scale convection are known to occur at a sub-km range. We may tentatively investigate these ultra-short horizontal scales, provided we perform a trade-off between spectral binning/resolution (which is not too stringent for UV absorber measurements at the expense of gaseous spectroscopy) and spatial/temporal binning. This ultra-high spatial observations campaigns may occur over known targets where coupling between surface topography and gravity waves is known to take place. However, these would amount to a small proportion of VeSUV observations if we want to achieve our global coverage of $\mathrm{SO}$ and $\mathrm{SO}_{2}$ measurements, as well as keeping data rate below our global allocation on board the spacecraft (936 Mbit per orbit as of January 2021).

\section{Conclusion}

We have shown here that it is indeed possible to build, with existing (or currently in development) technology, a two-channel UV spectral imager onboard a Venus orbiter that would allow for significant improvements compared with previous UV measurements of sulphur-bearing gases, cloud UV albedo and altitude. The improvement factors range from about 2 for $\mathrm{SO}_{2}$ abundance up to about 10 for $\mathrm{SO}: \mathrm{SO}_{2}$ ratio. Incidentally, other interesting measurements could be obtained during the occultations of calibration stars through the Venusian mesosphere to derive constraints of the vertical profiles of gaseous and particulate species above the clouds. Also, glory observations would allow us to retrieve microphysical properties of cloud aerosols, so that the complex interactive process of photochemistry (Shao et al., 2020) and cloud aerosol formation (McGouldrick, 2017) could be analyzed comprehensively.

The scientific potential of the VeSUV instrument is significant on its own. When the instrument is coupled with e.g. simultaneous and horizontally colocated high resolution day side or night side infrared spectroscopy, numerous other gaseous species (carbon monoxide, water vapor, carbonyl sulphide, hydrogen halides) can be measured over a broad altitude range, allowing for a more comprehensive assessment of the interplay between photochemistry and atmospheric dynamics at the cloud top of Venus, as well as any links between those processes and any active volcanism at the surface. The proposed ESA M5 mission concept EnVision, which proposes to include the spectrometer suite VenSpec including a multispectral infrared surface imager (Helbert et al., 2016), a high-resolution infrared spectrometer and our proposed UV instrument, would be ideally suited to accomplish these tasks.

Acknowledgements The development of the VenSpec-U experiment on-board the EnVision mission is an activity carried out under a programme of the European Space Agency. The activity is supported and funded by the European Space Agency (ESA), the French space agency (CNES), the French national centre for scientific research (CNRS), the University of Versailles Saint Quentin (UVSQ, France) and Sorbonne University (SU, France). The view expressed in this publication does not reflect the official opinion of the supporting and funding agencies. CFW acknowledges funding from the UK Space Agency grant ST/V003224/1. YJL has received funding from EU Horizon 2020 MSCA-IF N 841432. 
The UVI data we processed in $§ 3.2 .1$ can be accessed at the following DOIs. For Level 2 data: Murakami, S., M. Yamada, A. Yamazaki, K. McGouldrick, Y. Yamamoto, G. L. Hashimoto, Venus Climate Orbiter Akatsuki UVI Calibrated Data v1.0, VCO-V-UVI-3CDR-V1.0, NASA Planetary Data System, DOI:10.17597/ISAS.DARTS/VCO-00003, 2018. For geometry data: Murakami, S., M. Yamada, K. McGouldrick, Y. Yamamoto, G. L. Hashimoto, Venus Climate Orbiter Akatsuki UVI Geometry Information v1.0, VCO-V-UVI3-SEDR-V1.0, NASA Planetary Data System, DOI:10.17597/ISAS.DARTS/VCO-00004, 2018.

We also want to acknowledge the Crystal IS company, which has graciously provided us with ultraviolet leds for technical assessment.

We finally wish to thank the two anonymous reviewers for their helpful comments resulting in a much improved version of this work.

\section{Conflict of interest}

The authors declare that they have no conflict of interest.

\section{References}

Arney G, Meadows V, Crisp D, Schmidt SJ, Bailey J, Robinson T (2014) Spatially resolved measurements of $\mathrm{H}_{2} \mathrm{O}, \mathrm{HCl}, \mathrm{CO}, \mathrm{OCS}, \mathrm{SO}_{2}$, cloud opacity, and acid concentration in the Venus near-infrared spectral windows. Journal of Geophysical Research (Planets) 119:1860-1891, DOI 10.1002/2014JE004662

Barker ES (1979) Detection of $\mathrm{SO}_{2}$ in the UV spectrum of Venus. Geophys. Res. Lett.6:117-120, DOI 10.1029/GL006i002p00117

Barstow JK, Tsang CCC, Wilson CF, Irwin PGJ, Taylor FW, McGouldrick K, Drossart P, Piccioni G, Tellmann S (2012) Models of the global cloud structure on Venus derived from Venus Express observations. Icarus 217:542-560, DOI 10.1016/j.icarus.2011.05.018

Bertaux JL, Nevejans D, Korablev O, Villard E, Quémerais E, Neefs E, Montmessin F, Leblanc F, Dubois JP, Dimarellis E, Hauchecorne A, Lefèvre F, Rannou P, Chaufray JY, Cabane M, Cernogora G, Souchon G, Semelin F, Reberac A, van Ransbeek E, Berkenbosch S, Clairquin R, Muller C, Forget F, Hourdin F, Talagrand O, Rodin A, Fedorova A, Stepanov A, Vinogradov I, Kiselev A, Kalinnikov Y, Durry G, Sandel B, Stern A, Gérard JC (2007) SPICAV on Venus Express: Three spectrometers to study the global structure and composition of the Venus atmosphere. Plan and Space Sci 55:1673-1700, DOI 10.1016/j.pss.2007.01.016

Braak CJ, de Haan JF, Hovenier JW, Travis LD (2002) Spatial and temporal variations of Venus haze properties obtained from Pioneer Venus Orbiter polarimetry. Journal of Geophysical Research (Planets) 107(E5):5029, DOI 10.1029/2001JE001502

Dollfus A, Boyer C, Camichel H (1960) Commission des surfaces planétaires : Étude photographique de Vénus en lumière violette et ultra-violette. L'Astronomie 74:375 
Drossart P, Piccioni G, Adriani A, Angrilli F, Arnold G, Baines KH, Bellucci G, Benkhoff J, Bézard B, Bibring JP, Blanco A, Blecka MI, Carlson RW, Coradini A, Di Lellis A, Encrenaz T, Erard S, Fonti S, Formisano V, Fouchet T, Garcia R, Haus R, Helbert J, Ignatiev NI, Irwin PGJ, Langevin Y, Lebonnois S, Lopez-Valverde MA, Luz D, Marinangeli L, Orofino V, Rodin AV, Roos-Serote MC, Saggin B, Sanchez-Lavega A, Stam DM, Taylor FW, Titov D, Visconti G, Zambelli M, Hueso R, Tsang CCC, Wilson CF, Afanasenko TZ (2007) Scientific goals for the observation of Venus by VIRTIS on ESA/Venus express mission. Planet. Space Sci.55(12):1653-1672, DOI 10.1016/j.pss.2007.01.003

Encrenaz T, Greathouse TK, Roe H, Richter M, Lacy J, Bézard B, Fouchet T, Widemann $\mathrm{T}$ (2012) HDO and $\mathrm{SO}_{2}$ thermal mapping on Venus: evidence for strong $\mathrm{SO}_{2}$ variability. A\&A543:A153, DOI 10.1051/0004-6361/201219419

Encrenaz T, Greathouse TK, Richter MJ, Lacy J, Widemann T, Bézard B, Fouchet T, deWitt C, Atreya SK (2013) HDO and $\mathrm{SO}_{2}$ thermal mapping on Venus. II. The $\mathrm{SO}_{2}$ spatial distribution above and within the clouds. A\&A559:A65, DOI 10.1051/0004-6361/201322264

Encrenaz T, Greathouse TK, Richter MJ, DeWitt C, Widemann T, Bézard B, Fouchet T, Atreya SK, Sagawa $\mathrm{H}$ (2016) HDO and $\mathrm{SO}_{2}$ thermal mapping on Venus. III. Short-term and long-term variations between 2012 and 2016 . A\&A595:A74, DOI 10.1051/0004-6361/201628999

Encrenaz T, Greathouse TK, Marcq E, Sagawa H, Widemann T, Bézard B, Fouchet T, Lefèvre F, Lebonnois S, Atreya SK, Lee YJ, Giles R, Watanabe $\mathrm{S}$ (2019) HDO and $\mathrm{SO}_{2}$ thermal mapping on Venus. IV. Statistical analysis of the $\mathrm{SO}_{2}$ plumes. A\&A623:A70, DOI 10.1051/0004-6361/201833511

Encrenaz T, Greathouse TK, Marcq E, Sagawa H, Widemann T, Bézard B, Fouchet T, Lefèvre F, Lebonnois S, Atreya SK, Lee YJ, Giles R, Watanabe S, Shao W, Zhang X, Bierson CJ (2020a) HDO and $\mathrm{SO}_{2}$ thermal mapping on Venus. V. Evidence for a long-term anti-correlation. A\&A639:A69, DOI 10.1051/0004-6361/202037741

Encrenaz T, Greathouse TK, Marcq E, Widemann T, Bézard B, Fouchet T, Giles R, Sagawa H, Greaves J, Sousa-Silva C (2020b) A stringent upper limit of the $\mathrm{PH}_{3}$ abundance at the cloud top of Venus. A\&A643:L5, DOI 10.1051/0004-6361/202039559, 2010.07817

Esposito LW (1984) Sulfur dioxide - Episodic injection shows evidence for active Venus volcanism. Science 223:1072-1074, DOI $10.1126 /$ science.223.4640.1072

Esposito LW, Winick JR, Stewart AI (1979) Sulfur dioxide in the Venus atmosphere - Distribution and implications. Geophys. Res. Lett.6:601-604, DOI 10.1029/GL006i007p00601

Esposito LW, Copley M, Eckert R, Gates L, Stewart AIF, Worden H (1988) Sulfur dioxide at the Venus cloud tops, 1978-1986. J. Geophys. Res.93:52675276, DOI 10.1029/JD093iD05p05267

Frandsen BN, Wennberg PO, Kjaergaard HG (2016) Identification of OSSO as a near-UV absorber in the Venusian atmosphere. Geophys. Res. Lett.43(21):11,146-11,155, DOI 10.1002/2016GL070916 
Frandsen BN, Farahani S, Vogt E, Lane JR, Kjaergaard HG (2020) Spectroscopy of OSSO and Other Sulfur Compounds Thought to be Present in the Venus Atmosphere. Journal of Physical Chemistry A 124(35):7047-7059, DOI 10.1021/acs.jpca.0c04388

Fukuhara T, Futaguchi M, Hashimoto GL, Horinouchi T, Imamura T, Iwagaimi N, Kouyama T, Murakami SY, Nakamura M, Ogohara K, Sato M, Sato TM, Suzuki M, Taguchi M, Takagi S, Ueno M, Watanabe S, Yamada M, Yamazaki A (2017) Large stationary gravity wave in the atmosphere of Venus. Nature Geoscience 10(2):85-88, DOI 10.1038/ngeo2873

García Muñoz A, Pérez-Hoyos S, Sánchez-Lavega A (2014) Glory revealed in disk-integrated photometry of Venus. A\&A566:L1, DOI 10.1051/00046361/201423531, 1406.0277

Gérard JC, Cox C, Saglam A, Bertaux JL, Villard E, Nehmé C (2008) Limb observations of the ultraviolet nitric oxide nightglow with SPICAV on board Venus Express. Journal of Geophysical Research (Planets) 113(9):E00B03, DOI 10.1029/2008JE003078

Ghail R, Wilson C, Widemann T, Bruzzone L, Dumoulin C, Helbert J, Herrick R, Marcq E, Mason P, Rosenblatt P, Vandaele AC, Burtz LJ (2017) Envision: understanding why our most earth-like neighbour is so different. 1703.09010

Greaves JS, Richards AMS, Bains W, Rimmer PB, Sagawa H, Clements DL, Seager S, Petkowski JJ, Sousa-Silva C, Ranjan S, Drabek-Maunder E, Fraser HJ, Cartwright A, Mueller-Wodarg I, Zhan Z, Friberg P, Coulson I, Lee E, Hoge J (2020) Phosphine gas in the cloud decks of Venus. Nature Astronomy DOI 10.1038/s41550-020-1174-4, 2009.06593

Hapke B, Nelson R (1975) Evidence for an elemental sulfur component of the clouds from Venus spectrophotometry. Journal of Atmospheric Sciences 32:1212-1218, DOI 10.1175/1520-0469(1975)032¡1212:EFAESC ¿2.0.CO;2

Hartley KK, Wolff AR, Travis LD (1989) Croconic acid: An absorber in the Venus clouds? Icarus77(2):382-390, DOI 10.1016/0019-1035(89)90095-X

Haus R, Kappel D, Tellmann S, Arnold G, Piccioni G, Drossart P, Häusler B (2016) Radiative energy balance of Venus based on improved models of the middle and lower atmosphere. Icarus272:178-205, DOI 10.1016/j.icarus.2016.02.048

Helbert J, Wendler D, Walter I, Widemann T, Marcq E, Guignan G, Ferrari S, Maturilli A, Mueller N, Kappel D, et al. (2016) The venus emissivity mapper (vem) concept. In: Infrared Remote Sensing and Instrumentation XXIV, International Society for Optics and Photonics, vol 9973, p 99730R

Helbert J, Vandaele AC, Marcq E, Robert S, Ryan C, Guignan G, Rosas-Ortiz Y, Neefs E, Thomas IR, Arnold G, Peter G, Widemann T, Lara L (2019) The VenSpec suite on the ESA EnVision mission to Venus. In: Infrared Remote Sensing and Instrumentation XXVII, Society of Photo-Optical Instrumentation Engineers (SPIE) Conference Series, vol 11128, p 1112804, DOI $10.1117 / 12.2529248$

Heyden FJ, Kiess CC, Kiess HK (1959) Spectrum of Venus in the Violet and Near-Ultraviolet. Science 130(3383):1195, DOI 
10.1126/science.130.3383.1195

Horinouchi T, Kouyama T, Lee YJ, Murakami Sy, Ogohara K, Takagi M, Imamura T, Nakajima K, Peralta J, Yamazaki A, Yamada M, Watanabe S (2018) Mean winds at the cloud top of Venus obtained from twowavelength UV imaging by Akatsuki. Earth, Planets, and Space 70(1):10, DOI 10.1186/s40623-017-0775-3

Hueso R, Peralta J, Sánchez-Lavega A (2012) Assessing the long-term variability of Venus winds at cloud level from VIRTIS-Venus Express. Icarus 217:585-598, DOI 10.1016/j.icarus.2011.04.020

Hueso R, Peralta J, Garate-Lopez I, Bandos T, Snchez-Lavega A (2015) Six years of venus winds at the upper cloud level from uv, visible and near infrared observations from virtis on venus express. Planet. Space Sci.113114:78 - 99, DOI https://doi.org/10.1016/j.pss.2014.12.010, URL http://www.sciencedirect.com/science/article/pii/S0032063314004024, sI:Exploration of Venus

Imamura T, Higuchi T, Maejima Y, Takagi M, Sugimoto N, Ikeda K, Ando $\mathrm{H}$ (2014) Inverse insolation dependence of Venus' cloud-level convection. Icarus228:181-188, DOI 10.1016/j.icarus.2013.10.012

Jessup KL, Marcq E, Mills F, Mahieux A, Limaye S, Wilson C, Allen M, Bertaux JL, Markiewicz W, Roman T, Vandaele AC, Wilquet V, Yung Y (2015) Coordinated Hubble Space Telescope and Venus Express Observations of Venus' upper cloud deck. Icarus258:309-336, DOI 10.1016/j.icarus.2015.05.027

Kawabata K, Coffeen DL, Hansen JE, Lane WA, Sato M, Travis LD (1980) Cloud and haze properties from Pioneer Venus polarimetry. J. Geophys. Res.85:8129-8140, DOI 10.1029/JA085iA13p08129

Khatuntsev IV, Patsaeva MV, Titov DV, Ignatiev NI, Turin AV, Limaye SS, Markiewicz WJ, Almeida M, Roatsch T, Moissl R (2013) Cloud level winds from the Venus Express Monitoring Camera imaging. Icarus 226:140-158, DOI 10.1016/j.icarus.2013.05.018

Kitahara T, Imamura T, Sato TM, Yamazaki A, Lee YJ, Yamada M, Watanabe S, Taguchi M, Fukuhara T, Kouyama T, Murakami Sy, Hashimoto GL, Ogohara K, Kashimura H, Horinouchi T, Takagi M (2019) Stationary Features at the Cloud Top of Venus Observed by Ultraviolet Imager Onboard Akatsuki. Journal of Geophysical Research (Planets) 124(5):12661281, DOI 10.1029/2018JE005842

Knibbe WJJ, de Haan JF, Hovenier JW, Travis LD (1998) Analysis of temporal variations of the polarization of Venus observed by Pioneer Venus Orbiter. J. Geophys. Res.103(E4):8557-8574, DOI 10.1029/97JE03558

Kouyama T, Imamura T, Taguchi M, Fukuhara T, Sato TM, Yamazaki A, Futaguchi M, Murakami S, Hashimoto GL, Ueno M, Iwagami N, Takagi S, Takagi M, Ogohara K, Kashimura H, Horinouchi T, Sato N, Yamada M, Yamamoto Y, Ohtsuki S, Sugiyama K, Ando H, Takamura M, Yamada T, Satoh T, Nakamura M (2017) Topographical and Local Time Dependence of Large Stationary Gravity Waves Observed at the Cloud Top of Venus. Geophys. Res. Lett.44(24):12,098-12,105, DOI 10.1002/2017GL075792 
Krasnopolsky VA (2017) On the iron chloride aerosol in the clouds of Venus. Icarus286:134-137, DOI 10.1016/j.icarus.2016.10.003

Lee YJ, Imamura T, Schröder SE, Marcq E (2015) Long-term variations of the UV contrast on Venus observed by the Venus Monitoring Camera on board Venus Express. Icarus 253:1-15, DOI 10.1016/j.icarus.2015.02.015

Lee YJ, Yamazaki A, Imamura T, Yamada M, Watanabe S, Sato TM, Ogohara K, Hashimoto GL, Murakami S (2017) Scattering Properties of the Venusian Clouds Observed by the UV Imager on board Akatsuki. AJ154(2):44, DOI 10.3847/1538-3881/aa78a5

Lee YJ, Jessup KL, Perez-Hoyos S, Titov DV, Lebonnois S, Peralta J, Horinouchi T, Imamura T, Limaye S, Marcq E, Takagi M, Yamazaki A, Yamada M, Watanabe S, Murakami Sy, Ogohara K, McClintock WM, Holsclaw G, Roman A (2019) Long-term Variations of Venus's 365 nm Albedo Observed by Venus Express, Akatsuki, MESSENGER, and the Hubble Space Telescope. AJ158(3):126, DOI 10.3847/1538-3881/ab3120, 1907.09683

Lee YJ, García Muñoz A, Imamura T, Yamada M, Satoh T, Yamazaki A, Watanabe S (2020) Brightness modulations of our nearest terrestrial planet Venus reveal atmospheric super-rotation rather than surface features. Nature Communications 11:5720, DOI 10.1038/s41467-020-19385-6, 2011.09271

Lefèvre M, Spiga A, Lebonnois S (2017) Three-dimensional turbulenceresolving modeling of the Venusian cloud layer and induced gravity waves. Journal of Geophysical Research (Planets) 122(1):134-149, DOI 10.1002/2016JE005146

Lefèvre M, Lebonnois S, Spiga A (2018) Three-Dimensional TurbulenceResolving Modeling of the Venusian Cloud Layer and Induced Gravity Waves: Inclusion of Complete Radiative Transfer and Wind Shear. Journal of Geophysical Research (Planets) 123(10):2773-2789, DOI 10.1029/2018JE005679

Lefèvre M, Spiga A, Lebonnois S (2020) Mesoscale modeling of Venus' bow-shape waves. Icarus335:113376, DOI 10.1016/j.icarus.2019.07.010, 1902.07010

Limaye SS, Mogul R, Smith DJ, Ansari AH, Słowik GP, Vaishampayan P (2018) Venus' Spectral Signatures and the Potential for Life in the Clouds. Astrobiology 18(9):1181-1198, DOI 10.1089/ast.2017.1783

Marcq E, Belyaev D, Montmessin F, Fedorova A, Bertaux JL, Vandaele $\mathrm{AC}$, Neefs $\mathrm{E}$ (2011) An investigation of the $\mathrm{SO}_{2}$ content of the venusian mesosphere using SPICAV-UV in nadir mode. Icarus 211:58-69, DOI 10.1016/j.icarus.2010.08.021

Marcq E, Bertaux JL, Montmessin F, Belyaev D (2013) Variations of sulphur dioxide at the cloud top of Venus's dynamic atmosphere. Nature geoscience 6(1):25-28, DOI 10.1038/ngeo1650, URL http://hal.archivesouvertes.fr/hal-00767475

Marcq E, Baggio L, Lefèvre F, Stolzenbach A, Montmessin F, Belyaev D, Korablev O, Bertaux JL (2019) Discovery of cloud top ozone on Venus. Icarus319:491-498, DOI 10.1016/j.icarus.2018.10.006 
Marcq E, Lea Jessup K, Baggio L, Encrenaz T, Lee YJ, Montmessin F, Belyaev D, Korablev O, Bertaux JL (2020) Climatology of $\mathrm{SO}_{2}$ and UV absorber at Venus' cloud top from SPICAV-UV nadir dataset. Icarus335:113368, DOI 10.1016/j.icarus.2019.07.002

Markiewicz WJ, Titov DV, Ignatiev N, Keller HU, Crisp D, Limaye SS, Jaumann R, Moissl R, Thomas N, Esposito L, Watanabe S, Fiethe B, Behnke T, Szemerey I, Michalik H, Perplies H, Wedemeier M, Sebastian I, Boogaerts W, Hviid SF, Dierker C, Osterloh B, Böker W, Koch M, Michaelis H, Belyaev D, Dannenberg A, Tschimmel M, Russo P, Roatsch T, Matz KD (2007) Venus Monitoring Camera for Venus Express. Planet. Space Sci.55(12):1701-1711, DOI 10.1016/j.pss.2007.01.004

Markiewicz WJ, Petrova E, Shalygina O, Almeida M, Titov DV, Limaye SS, Ignatiev N, Roatsch T, Matz KD (2014) Glory on Venus cloud tops and the unknown UV absorber. Icarus234:200-203, DOI 10.1016/j.icarus.2014.01.030

Markiewicz WJ, Petrova EV, Shalygina OS (2018) Aerosol properties in the upper clouds of Venus from glory observations by the Venus Monitoring Camera (Venus Express mission). Icarus299:272-293, DOI 10.1016/j.icarus.2017.08.011

McGouldrick K (2017) Effects of variation in coagulation and photochemistry parameters on the particle size distributions in the Venus clouds. Earth, Planets, and Space 69(1):161, DOI 10.1186/s40623-017-0744-x

Mills FP, Allen M (2007) A review of selected issues concerning the chemistry in Venus' middle atmosphere. Planet. Space Sci.55:1729-1740, DOI $10.1016 /$ j.pss.2007.01.012

Molaverdikhani K, McGouldrick K, Esposito LW (2012) The abundance and vertical distribution of the unknown ultraviolet absorber in the venusian atmosphere from analysis of Venus Monitoring Camera images. Icarus 217:648-660, DOI 10.1016/j.icarus.2011.08.008

Montmessin F, Bertaux JL, Lefèvre F, Marcq E, Belyaev D, Gérard JC, Korablev O, Fedorova A, Sarago V, Vandaele AC (2011) A layer of ozone detected in the nightside upper atmosphere of Venus. Icarus 216:82-85, DOI 10.1016/j.icarus.2011.08.010

Na CY, Esposito LW, Skinner TE (1990) International Ultraviolet Explorer observations of Venus $\mathrm{SO}_{2}$ and SO. J. Geophys. Res.95:7485-7491, DOI 10.1029/JD095iD06p07485

Na CY, Esposito LW, McClintock WE, Barth CA (1994) Sulfur dioxide in the atmosphere of Venus. 2: Modeling results. Icarus 112:389-395, DOI 10.1006/icar.1994.1193

Nakamura M, Imamura T, Ishii N, Abe T, Kawakatsu Y, Hirose C, Satoh T, Suzuki M, Ueno M, Yamazaki A, Iwagami N, Watanabe S, Taguchi M, Fukuhara T, Takahashi Y, Yamada M, Imai M, Ohtsuki S, Uemizu K, Hashimoto GL, Takagi M, Matsuda Y, Ogohara K, Sato N, Kasaba Y, Kouyama T, Hirata N, Nakamura R, Yamamoto Y, Horinouchi T, Yamamoto M, Hayashi YY, Kashimura H, Sugiyama Ki, Sakanoi T, Ando H, Murakami Sy, Sato TM, Takagi S, Nakajima K, Peralta J, Lee YJ, Nakatsuka J, Ichikawa T, Inoue K, Toda T, Toyota H, Tachikawa S, Narita S, 
Hayashiyama T, Hasegawa A, Kamata Y (2016) AKATSUKI returns to Venus. Earth, Planets, and Space 68(1):75, DOI 10.1186/s40623-016-0457-6

Navarro T, Schubert G, Lebonnois S (2018) Atmospheric mountain wave generation on Venus and its influence on the solid planet's rotation rate. Nature Geoscience 11(7):487-491, DOI 10.1038/s41561-018-0157-x

Newville M, Otten R, Nelson A, Ingargiola A, Stensitzki T, Allan D, Fox A, Carter F, Micha, Pustakhod D, et al (2020) lmfit/lmfit-py 1.0.1 DOI 10.5281/zenodo.3814709

Parkinson W (2003) Absolute absorption cross section measurements of $\mathrm{CO}_{2}$ in the wavelength region 163-200 nm and the temperature dependence. Chemical Physics 290:251-256, DOI 10.1016/S0301-0104(03)00146-0

Peralta J, Hueso R, Sánchez-Lavega A, Piccioni G, Lanciano O, Drossart P (2008) Characterization of mesoscale gravity waves in the upper and lower clouds of Venus from VEX-VIRTIS images. Journal of Geophysical Research (Planets) 113:E00B18, DOI 10.1029/2008JE003185

Peralta J, Hueso R, Sánchez-Lavega A, Lee YJ, Muñoz AG, Kouyama T, Sagawa H, Sato TM, Piccioni G, Tellmann S, Imamura T, Satoh T (2017) Stationary waves and slowly moving features in the night upper clouds of Venus. Nature Astronomy 1:0187, DOI 10.1038/s41550-017-0187, 1707.07796

Pérez-Hoyos S, Sánchez-Lavega A, García-Muñoz A, Irwin PGJ, Peralta J, Holsclaw G, McClintock WM, Sanz-Requena JF (2018) Venus Upper Clouds and the UV Absorber From MESSENGER/MASCS Observations. Journal of Geophysical Research (Planets) 123(1):145-162, DOI 10.1002/2017JE005406, 1801.03820

Petrova EV, Shalygina OS, Markiewicz WJ (2015a) The VMC/VEx photometry at small phase angles: Glory and the physical properties of particles in the upper cloud layer of Venus. Planet. Space Sci.113:120-134, DOI 10.1016/j.pss.2014.11.013

Petrova EV, Shalygina OS, Markiewicz WJ (2015b) UV contrasts and microphysical properties of the upper clouds of Venus from the UV and NIR VMC/VEx images. Icarus260:190-204, DOI 10.1016/j.icarus.2015.07.015

Phillips LF (1981) Absolute absorption cross sections for SO between 190 and $235 \mathrm{~nm}$. Journal of Physical Chemistry 85:3994-4000

Piccialli A, Titov DV, Sanchez-Lavega A, Peralta J, Shalygina O, Markiewicz WJ, Svedhem H (2014) High latitude gravity waves at the Venus cloud tops as observed by the Venus Monitoring Camera on board Venus Express. Icarus 227:94-111, DOI 10.1016/j.icarus.2013.09.012

Pollack JB, Ragent B, Boese RW, Tomasko MG, Blamont J, Knollenberg RG, Esposito LW, Stewart AI, Travis L (1979) Nature of the Ultraviolet Absorber in the Venus Clouds: Inferences Based on Pioneer Venus Data. Science 205(4401):76-79, DOI 10.1126/science.205.4401.76

Pollack JB, Toon OB, Whitten RC, Boese R, Ragent B, Tomasko M, Eposito L, Travis L, Wiedman D (1980) Distribution and source of the UV absorption in Venus' atmosphere. J. Geophys. Res.85:8141-8150, DOI 10.1029/JA085iA13p08141 
Ross FE (1928) Photographs of Venus. ApJ68:57, DOI 10.1086/143130

Rossi L, Marcq E, Montmessin F, Fedorova A, Stam D, Bertaux JL, Korablev O (2015) Preliminary study of Venus cloud layers with polarimetric data from SPICAV/VEx. Planetary and Space Science 113114:159 - 168, DOI http://dx.doi.org/10.1016/j.pss.2014.11.011, sI:Exploration of Venus

Royer EM, Montmessin F, Marcq E (2016) Variability of the nitric oxide nightglow at Venus during solar minimum. Journal of Geophysical Research (Planets) 121(5):846-853, DOI 10.1002/2016JE005013

Sánchez-Lavega A, Peralta J, Gomez-Forrellad JM, Hueso R, Pérez-Hoyos S, Mendikoa I, Rojas JF, Horinouchi T, Lee YJ, Watanabe S (2016) Venus Cloud Morphology and Motions from Ground-based Images at the Time of the Akatsuki Orbit Insertion. ApJ833(1):L7, DOI 10.3847/20418205/833/1/L7, 1611.04318

Sánchez-Lavega A, Lebonnois S, Imamura T, Read P, Luz D (2017) The Atmospheric Dynamics of Venus. Space Sci. Rev.212(3-4):1541-1616, DOI 10.1007/s11214-017-0389-x

Sander S, Friedl R, Barker J, Golden D, Kurylo M, Wine P, Abbatt J, Burkholder J, Kolb C, Moortgat G, et al. (2003) Chemical kinetics and photochemical data for use in atmospheric studies, evaluation number 14 . JPL Publ, 02 25:334

Shao WD, Zhang X, Bierson CJ, Encrenaz T (2020) Revisiting the SulfurWater Chemical System in the Middle Atmosphere of Venus. Journal of Geophysical Research (Planets) 125(8):e06195, DOI 10.1029/2019JE006195, 2006.09522

Sneep M, Ubachs W (2005) Direct measurement of the Rayleigh scattering cross section in various gases. Journal of Quantitative Spectroscopy and Radiative Transfer 92:293-310, DOI 10.1016/j.jqsrt.2004.07.025

Stiepen A, Gérard JC, Dumont M, Cox C, Bertaux JL (2013) Venus nitric oxide nightglow mapping from SPICAV nadir observations. Icarus226(1):428 436, DOI 10.1016/j.icarus.2013.05.031

Titov DV, Svedhem H, McCoy D, Lebreton JP, Barabash S, Bertaux JL, Drossart P, Formisano V, Haeusler B, Korablev OI, Markiewicz W, Neveance D, Petzold M, Piccioni G, Zhang TL, Taylor FW, Lellouch E, Koschny D, Witasse O, Warhaut M, Acomazzo A, Rodrigues-Cannabal J, Fabrega J, Schirmann T, Clochet A, Coradini M (2006) Venus Express: Scientific goals, instrumentation, and scenario of the mission. Cosmic Research 44:334-348, DOI 10.1134/S0010952506040071

Titov DV, Taylor FW, Svedhem H, Ignatiev NI, Markiewicz WJ, Piccioni G, Drossart P (2008) Atmospheric structure and dynamics as the cause of ultraviolet markings in the clouds of Venus. Nature456:620-623, DOI 10.1038/nature07466

Titov DV, Markiewicz WJ, Ignatiev NI, Song L, Limaye SS, Sanchez-Lavega A, Hesemann J, Almeida M, Roatsch T, Matz KD, Scholten F, Crisp D, Esposito LW, Hviid SF, Jaumann R, Keller HU, Moissl R (2012) Morphology of the cloud tops as observed by the Venus Express Monitoring Camera. Icarus217(2):682-701, DOI 10.1016/j.icarus.2011.06.020 
Toon OB, Pollack JB, Turco RP (1982) The ultraviolet absorber on Venus Amorphous sulfur. Icarus 51:358-373, DOI 10.1016/0019-1035(82)90089-6

Vandaele AC, Korablev O, Belyaev D, Chamberlain S, Evdokimova D, Encrenaz T, Esposito L, Jessup KL, Lefèvre F, Limaye S, Mahieux A, Marcq E, Mills FP, Montmessin F, Parkinson CD, Robert S, Roman T, Sandor B, Stolzenbach A, Wilson C, Wilquet V (2017a) Sulfur dioxide in the Venus atmosphere: I. Vertical distribution and variability. Icarus295:16-33, DOI 10.1016/j.icarus.2017.05.003

Vandaele AC, Korablev O, Belyaev D, Chamberlain S, Evdokimova D, Encrenaz T, Esposito L, Jessup KL, Lefèvre F, Limaye S, Mahieux A, Marcq E, Mills FP, Montmessin F, Parkinson CD, Robert S, Roman T, Sandor B, Stolzenbach A, Wilson C, Wilquet V (2017b) Sulfur dioxide in the Venus Atmosphere: II. Spatial and temporal variability. Icarus295:1-15, DOI 10.1016/j.icarus.2017.05.001

Vlasov P, D'Aversa E, Belyaev D, Ignatiev N, Bertaux JL, Marcq E, Baggio L, Piccioni G, Carlson R (2019) Ultraviolet albedo of Venus' clouds due to SPICAV and VIRTIS joint nadir observations onboard Venus Express. In: EPSC-DPS Joint Meeting 2019, vol 2019, pp EPSC-DPS2019-1597

Watson AJ, Donahue TM, Stedman DH, Knollenberg RG, Ragent B, Blamont J (1979) Oxides of nitrogen and the clouds of Venus. Geophys. Res. Lett.6(9):743-746, DOI 10.1029/GL006i009p00743

Yamazaki A, Yamada M, Lee YJ, Watanabe S, Horinouchi T, Murakami Sy, Kouyama T, Ogohara K, Imamura T, Sato T, Yamamoto Y, Fukuhara T, Ando H, Sugiyama Ki, Takagi S, Kashimura H, Ohtsuki S, Hirata N, Hashimoto G, Nakamura M (2018) Ultraviolet imager on venus orbiter akatsuki and its initial results. Earth, Planets and Space 70, DOI 10.1186/s40623-017-0772-6

Zasova LV, Krasnopolskii VA, Moroz VI (1981) Vertical distribution of $\mathrm{SO}_{2}$ in upper cloud layer of Venus and Origin of U.V.-absorption. Advances in Space Research 1(9):13-16, DOI 10.1016/0273-1177(81)90213-1

Zhang X, Liang MC, Mills FP, Belyaev DA, Yung YL (2012) Sulfur chemistry in the middle atmosphere of Venus. Icarus217(2):714-739, DOI 10.1016/j.icarus.2011.06.016 